\title{
BEYOND 2020 - STRATEGIES AND COSTS FOR TRANSFORMING THE EUROPEAN ENERGY SYSTEM
}

\author{
BRIGITTE KNOPF, ${ }^{*}$, YEN-HENG HENRY CHEN ${ }^{\dagger}$, ENRICA DE CIAN ${ }^{\star}$, \\ HANNAH FÖRSTER ${ }^{\S}$, AMIT KANUDIA ${ }^{\uparrow}$, IOANNA KARKATSOULI ${ }^{\dagger}$, \\ ILKKA KEPPO $\|$, TIINA KOLJONEN ${ }^{* *}$, KATJA SCHUMACHER ${ }^{\S}$ \\ and DETLEF P. VAN VUUREN ${ }^{\dagger \dagger, H t}$ \\ *Potsdam Institute for Climate Impact Research (PIK) \\ Research Domain III: Sustainable Solutions \\ P.O. Box 6012 03, 14412 Potsdam, Germany \\ ${ }^{\dagger}$ Massachusetts Institute of Technology (MIT) \\ Joint Program on the Science and Policy of Global Change \\ 77 Massachusetts Avenue, E19-411, Cambridge, MA 02139, USA \\ Fondazione Eni Enrico Mattei (FEEM) \\ Euro-Mediterranean Center on Climate Change (CMCC) \\ Isola di San Giorgio Maggiore, 30124 Venezia, Italy \\ ${ }^{\S}$ Öko-Institut, Schicklerstraße 5-7, 10179 Berlin, Germany \\ "KanORS-EMR, SDF L-7B, NSEZ \\ Dadri Road Phase II, Noida UP 201305, India \\ "University College London, UCL Energy Institute \\ 14 Upper Woburn Place, London, WC1H ONN, UK \\ **VTT Technical Research Centre of Finland \\ P. O. Box 1000, 02044 VTT, Finland \\ ${ }^{\dagger} P B L$ Netherlands Environmental Assessment Agency \\ P. O. Box 30314, 2500 GH, The Hague, Netherlands \\ tDepartment of Geosciences, Utrecht University \\ Heidelberglaan 2, 3584 CS, Utrecht Netherlands \\ §snopf@pik-potsdam.de
}

Published 5 December 2013

\begin{abstract}
The Energy Modeling Forum 28 (EMF28) study systematically explores the energy system transition required to meet the European goal of reducing greenhouse gas (GHG) emissions by $80 \%$ by 2050 . The $80 \%$ scenario is compared to a reference case that aims to achieve a $40 \%$ GHG reduction target. The paper investigates mitigation strategies beyond 2020 and the interplay between different decarbonization options. The models present different technology pathways for the decarbonization of Europe, but a common finding across the scenarios and
\end{abstract}

\footnotetext{
$\S \S$ Corresponding author.

This is an Open Access article published by World Scientific Publishing Company. It is distributed under the terms of the Creative Commons Attribution 3.0 (CC-BY) License. Further distribution of this work is permitted, provided the original work is properly cited.
} 


\section{B. Knopf et al.}

models is the prominent role of energy efficiency and renewable energy sources. In particular, wind power and bioenergy increase considerably beyond current deployment levels. Up to 2030, the transformation strategies are similar across all models and for both levels of emission reduction. However, mitigation becomes more challenging after 2040. With some exceptions, our analysis agrees with the main findings of the "Energy Roadmap 2050" presented by the European Commission.

Keywords: European decarbonisation; mitigation scenarios; model comparison; climate change; EU Energy Roadmap 2050.

\section{Introduction}

\subsection{Setting the scene: The European Union's low-carbon strategy}

In 2009, the European Union (EU) set an aspirational target of reducing greenhouse gas (GHG) emissions by 80-95\% below 1990 levels by 2050 (European Council, 2009, confirmed in European Council, 2011). This objective reflects the EU's unilateral commitment to keeping increases in the global average temperature below $2^{\circ} \mathrm{C}$. The EU's long-term goal is grounded in a 2020 mid-term strategy described in the "EU climate and energy package" that aims to achieve: (i) a $20 \%$ reduction in EU GHG emissions from 1990 levels, (ii) raising the share of renewables in the EU's final energy consumption to $20 \%$ (including a $10 \%$ renewable share in the transport sector), and (iii) a $20 \%$ improvement in the EU's energy efficiency. Taken together, these goals constitute the 20-20-20 targets. ${ }^{1}$ While the first two targets are binding, the last one is only indicative. Furthermore, it remains unclear whether and how these targets will be maintained after 2020. An initial idea for a post 2020 framework was circulated in March 2013 with the EU green paper "A 2030 framework for climate and energy policies" (European Commission, 2013a) designed to launch a public consultation.

In 2011, the European Commission began a discussion about the long-term framework of climate and energy policies in Europe, including a strategy leading up to 2050. As a result, three roadmaps have been launched: the "Roadmap for Moving to a Competitive Low Carbon Economy in 2050" (European Commission, 2011d), the "Roadmap to a Single European Transport Area - Towards a Competitive and Resource Efficient Transport System" (European Commission, 2011f) and the "Energy Roadmap 2050" (European Commission, 2011e). Extensive modeling work has supported the three roadmaps, e.g., the impact assessment on the Energy Roadmap (European Commission, 2011c). The analyses of the energy system were mainly based on one model, i.e., PRIMES (E3Mlab, 2010). However, the single-model approach leaves several unanswered questions, particularly in terms of the modeling methodology, uncertainties related to input assumptions, and lack of transparency (see the critique by the Advisory Group on the Energy Roadmap (European Commission, 2011b)). Other single-model analyses of long-term EU climate and energy policies include Hübler and Löschel's (2013) analysis of the Energy Roadmap with a detailed

\footnotetext{
${ }^{1}$ For more information consult http://ec.europa.eu/clima/policies/package/index_en.htm.
} 
sectoral analysis. The study "Power Choices" focuses solely on the power sector using PRIMES (Eurelectric, 2009) and the "Roadmap 2050" by the European Climate Foundation (2011), is another example which investigates a number of pathways with different shares of renewables. However, earlier model comparison projects have taught us that mitigation strategies vary significantly across models (Weyant, 2004; Clarke et al., 2009; Edenhofer et al., 2010; Calvin et al., 2012; Luderer et al., 2012). In light of this, it seems that a multi-model perspective is valuable for formulating robust and effective energy and climate policies.

This paper contributes to the energy and climate debate by presenting the results of the Energy Modeling Forum 28 (EMF28). The project considers how to decarbonize the European energy system and asks whether the technology strategies drawn from the Energy Roadmap are robust when comparing them with the results of several models run by a number of organizations. More specifically, the research questions are:

- Technologies and sectors: Which are the most important technologies enabling the GHG reduction target to be met across the EU in a cost-effective manner? Are some technologies irrelevant or ambiguous? What is the most cost-effective allocation of emission reductions across sectors?

- Targets and timing: What are the implications of different long-term targets for shorter-term actions in terms of the timing of mitigation and for specifying targets? Are the EU 2020 targets sufficient to meet the long-term target of reducing GHG emissions by $80 \%$ by 2050 ? What does this imply for determining appropriate targets in 2030 and 2040? How do the costs of the transformation develop over time?

A total of 13 European modeling teams - including the PRIMES team - are involved in the model comparison under the roof of the Stanford EMF which is documented as the EMF28 study. ${ }^{2}$ The model typology ranges from global integrated assessment models, where Europe is modeled as one region, to European energy system models, which feature a greater level of spatial detail and an explicit representation of individual Member States. The EMF28 analysis builds upon the scenarios defined in the European Commission's Energy Roadmap. One set of scenarios considers the continuation of current policies, leading to a $40 \%$ reduction of GHG emissions by 2050 compared to 1990 . The decarbonization scenarios aim to reduce GHG emissions by $80 \%$ by the same date. This exercise has two goals. The first is to identify common technological requirements and technology portfolios by analyzing the various low carbon pathways produced by the models. The second is to understand the extent to which variations in results are due to assumptions inherent in the input data, and the extent to which they are explained by methodological differences. The underlying research question is whether different types of models tell different stories about Europe's decarbonization pathway, or whether there is a shared view on cost-effective strategies. The

\footnotetext{
${ }^{2}$ EMF has considerable experience in leading model comparison studies. Moreover, this EMF28 study, which focuses on the EU, was linked to similar studies at the global (EMF27) and USA scale (EMF24).
} 
use of a large number of models provides a wider characterization of plausible pathways, thus making it possible to attempt to identify robust strategies (Lempert, 2002).

This paper is organized as follows: The remainder of Sec. 1 introduces the scenarios and the participating models. Section 2 focuses on technology options and sectoral decarbonization strategies. Section 3 discusses the feasibility and costs of decarbonization. Potential EU targets for the period beyond 2020 are analyzed in Sec. 4. Section 5 presents the conclusions of this study and compares them to those of the Energy Roadmap.

\subsection{Scenario setup}

The EMF28 exercise incorporates two dimensions of analysis: (i) the availability of different technologies and (ii) the presence of different climate policy regimes outside Europe. Table 1 summarizes the main characteristics of the EMF28 scenarios. This paper specifically concentrates on the technology dimension of different European strategies, while De Cian et al. (2013) focus on the impacts of different global climate policy regimes for Europe.

The no-policy baseline scenario ${ }^{3}$ (BASE) describes a counter-factual baseline that does not include any target for 2020 or 2050. The purpose of this scenario is to determine how the models would behave without any constraint. The Reference scenarios achieve a $40 \%$ reduction of GHG emissions by 2050. These scenarios can be interpreted as a continuation of current policies (European Commission, 2011e, p. 2). The Mitigation 1 scenarios assume that the EU takes leadership of the global climate policy regime by committing unilaterally to an emissions reduction target of $80 \%$, while the rest of the world continues with moderate targets (Luderer et al., forthcoming). ${ }^{4}$ Furthermore, in these scenarios, only Europe has an established carbon market where carbon offsets can be exchanged. Mitigation 2 and 3 scenarios explore the role of international trade in carbon offset, see De Cian et al. (2013).

The Reference scenarios and the Mitigation 1, 2, and 3 scenarios consider technology variations in five main technology storylines. In the default cases $(40 \% \mathrm{DEF} /$ $80 \% \mathrm{DEF}$ ), the technology assumptions reflect the default view and structure of each model. ${ }^{5}$ The other scenarios consider a "what-if" perspective and analyze what happens if a certain technology is not available or if some technological development is

\footnotetext{
${ }^{3}$ This scenario should not be confused with the "business-as-usual" scenario of the Energy Roadmap. In the EMF28 baseline scenario, no policies are assumed, while in the "business-as-usual" scenario of the Energy Roadmap, the 2020-20 targets will be achieved and the annual reduction of the cap in the ETS directive is in place. The EMF28 baseline scenario has no corresponding scenario in the Energy Roadmap.

${ }^{4}$ The moderate policy scenarios for the rest of the world are taken from the WeakPol scenario in the RoSE project (Luderer et al., forthcoming). It reflects existing climate policies, a weak interpretation of the 2020 Copenhagen Pledges, and an extrapolation of these targets beyond 2020 based on the intensity of emissions (GHG emissions per unit of GDP). There is no international cooperation and international carbon trading is excluded.

${ }^{5}$ Default technology assumptions represent model-specific, evolutionary improvements in technology, while optimistic technology assumptions represent plausible, optimistic improvements. Pessimistic cases assume either the failure of a technology or public opposition.
} 


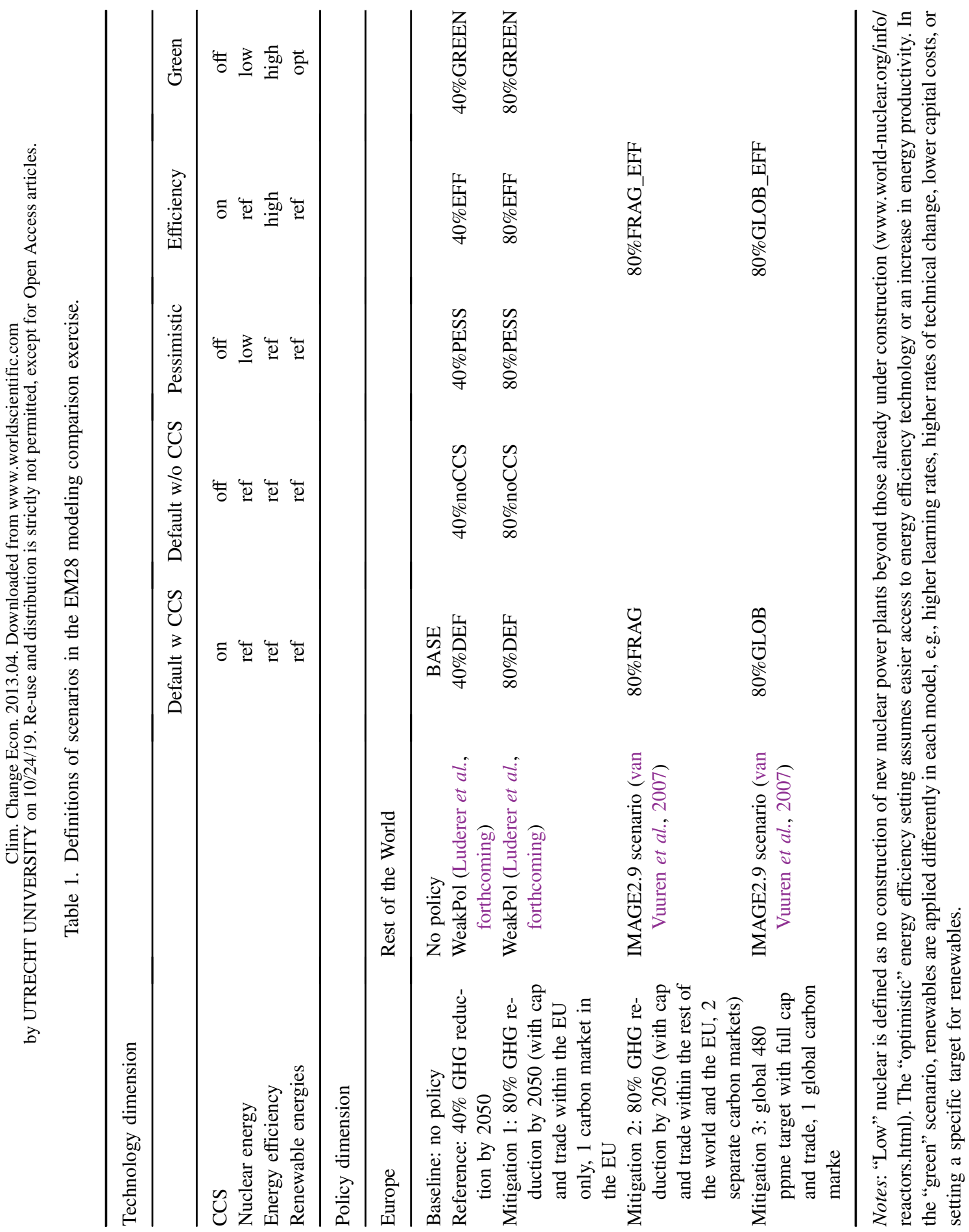




\section{B. Knopf et al.}

more successful than expected in the default case. In the $40 \%$ noCCS/80\%noCCS scenarios, carbon capture, and storage (CCS) is excluded ${ }^{6}$ and in the pessimistic scenarios 40\%PESS/80\%PESS both CCS and nuclear fission are excluded. CCS and nuclear fission could both be key elements of a mitigation strategy but are also controversial. An optimistic case considers expectations about greater efficiency improvements $(40 \% \mathrm{EFF} / 80 \% \mathrm{EFF})$, compared to the default assumptions. Green scenarios consider a situation without CCS and with low nuclear deployment, but with high energy efficiency and a more rapid technology development for renewable energy (40\%GREEN/80\%GREEN). The technology scenarios should be understood as reflecting "what-if" assumptions about technological development. To different degrees, the scenarios reflect public choice, technology failure, or success or failure of government policies. Within this set, the $40 \% \mathrm{DEF}$ and the $80 \% \mathrm{DEF}$ scenarios form the default reference and default mitigation scenario, respectively; 40\%DEF corresponds to the "Reference" scenario within the Energy Roadmap and 80\%DEF represents the "diversified supply technologies" scenario.

At the EU level, all scenarios except the baseline scenario take into account the 2020 target for GHG reduction. This target is considered a minimum, i.e., a GHG reduction of at least $20 \%$ has to be achieved by 2020. Models may however choose to implement a reduction rate based on the cost-efficiencies of reaching the long-term target. The EU target regarding share of renewables is only considered by two-thirds of the models, and again, where implemented this target is regarded as a minimum. The energy efficiency target is not incorporated in the models, as it is only indicative rather than binding. The analysis focuses on two different periods: the short-term action from 2010-2030 and the long-term requirements between 2030 and 2050.

Only a limited import of biofuels is allowed into the EU region by the scenarios. Although the Energy Roadmap acknowledges the importance of bioenergy as a mitigation option, land-based bioenergy options must be compatible with other biodiversity objectives as well as with the sustainability of agriculture and food security (European Parliament and the European Council, 2009, Art. 17, European Commission, 2011a, p.106). Europe interacts with the rest of the world through international trade, energy markets, and technology spill overs in all of the scenarios. However, the extent of these interactions is model-specific.

This paper identifies robust model results for the transformation of the European energy system (EU27) by focusing on the differences between the core scenarios (40\% $\mathrm{DEF}$ and $80 \% \mathrm{DEF}$ ) while taking into account different technological developments. De Cian et al. (2013) explore the implications of different global climate policy regimes by looking at the policy dimensions described in Table 1 and by focusing on the Mitigation 2 (80\%FRAG/80\%FRAG_EFF) and Mitigation 3 (80\%GLOB/80\%

\footnotetext{
${ }^{6} \mathrm{CCS}$ is excluded for any option that might be combined with this technology, coal, oil, gas, and bioenergy. Note that PRIMES provides the results of the "delayed CCS" scenario of the EU Energy Roadmap with limited CCS (instead of no CCS).
} 
Beyond 2020 - Strategies and Costs for Transforming the European Energy System

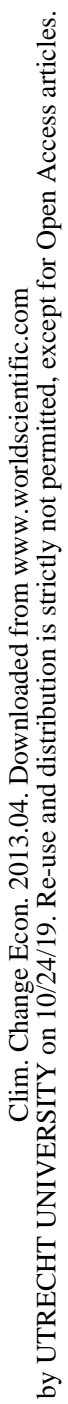

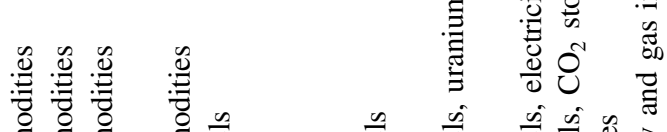

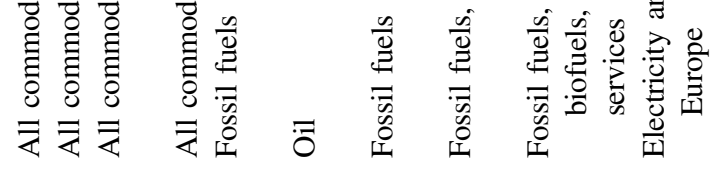

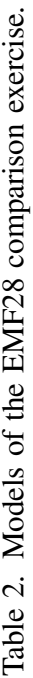

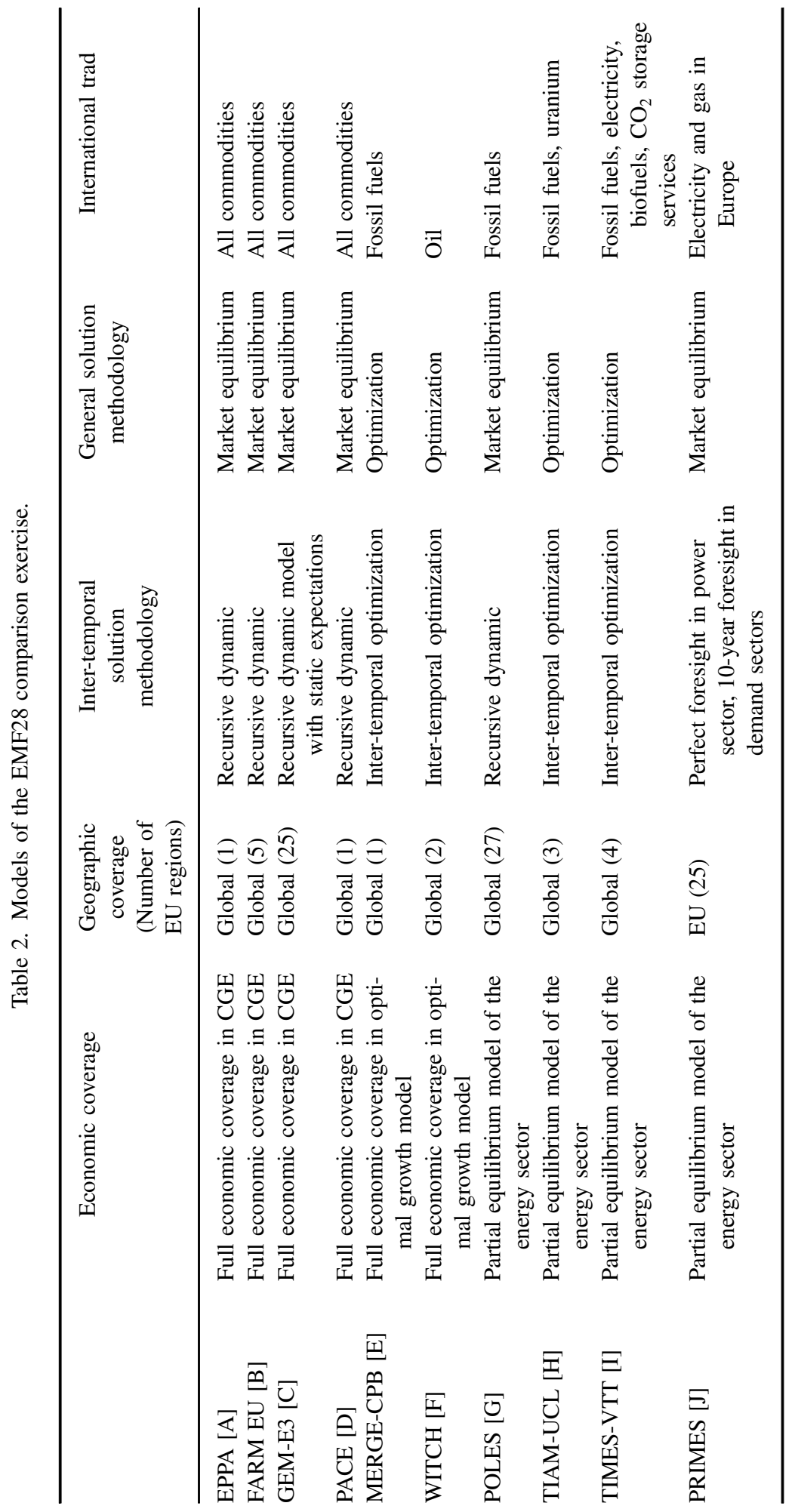




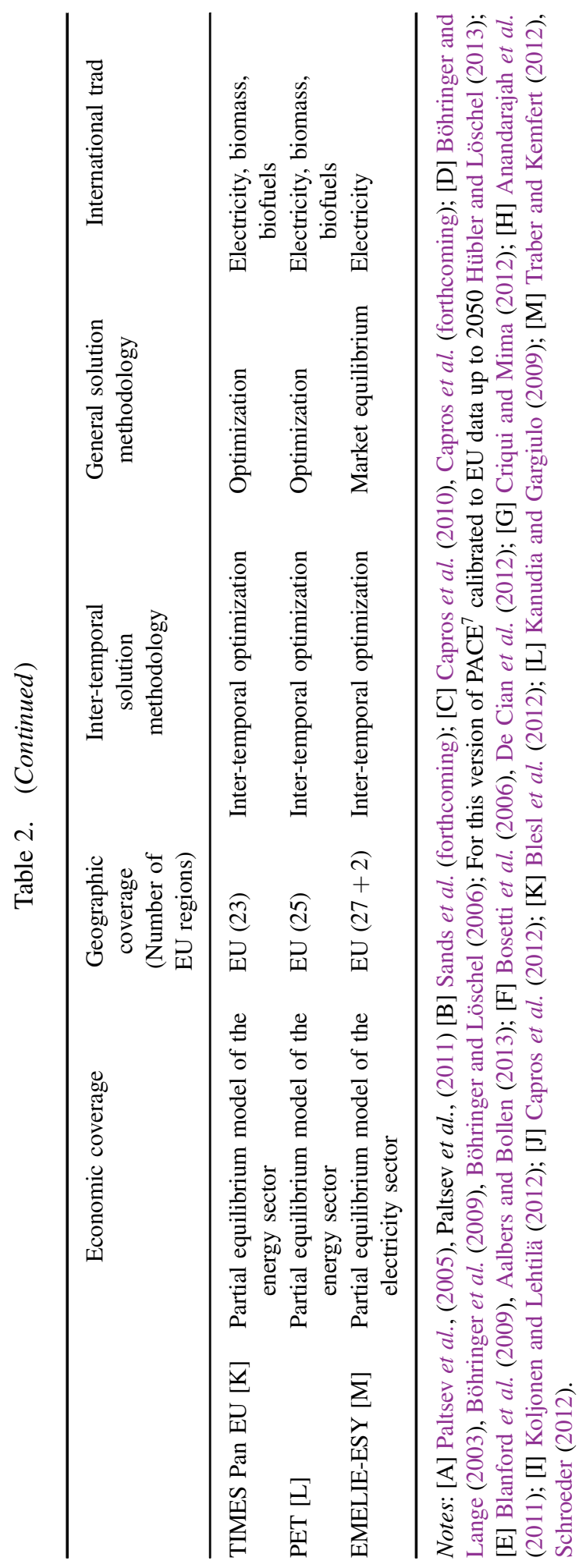


GLOB_EFF) scenarios. Other papers in this issue provide a structural analysis of the different decarbonization strategies (Förster et al., 2013) and compare alternative mitigation cost metrics (Paltsev and Capros, 2013). Knopf et al. (2013) explore the interplay between the transformation of the energy system at the European level and at the level of EU Member States. Holz and von Hirschhausen (2013) describe the infrastructure requirements for the EMF28 scenarios.

\subsection{Participating models}

The models included in this exercise differ in many respects. The main difference concerns the methodological characteristics of the models (i.e., energy system models and full equilibrium macro-economic models). Other differences include the geographical resolution (coverage and geographical explicitness), temporal resolution (model time horizon and time-step length), and sectoral coverage (focusing on the energy sector or coupling with other issues such as land-use).

Table 2 lists the models participating in the EMF28 exercise. There are two major classes of models: (i) macroeconomic models that describe the nexus between the economy and the energy system and (ii) partial equilibrium models of the energy system. The macroeconomic models include computable general equilibrium (CGE) models, which are solved recursively using market equilibrium conditions, and growth models, which are solved in a forward-looking manner using optimization algorithms. CGE and optimization models provide full economic coverage with the former representing all sectors of the economy in greater detail than the latter. The energy system models include a partial equilibrium representation of the full energy system. An additional model that covers the electricity sector in detail is also included. The majority of the models have a global scope and include trade in fossil fuels. Some models also include trade in biofuels, electricity, and captured $\mathrm{CO}_{2}$. Trade in other commodities is modeled in the CGE models. Finally, trade in emissions permits is dependent on the scenario definition and is not allowed in the reference or Mitigation 1 scenarios, except within the EU region.

\section{EU Decarbonization Strategies - Technology Options}

\subsection{Decarbonization challenges and strategies}

Figure 1 shows the $\mathrm{CO}_{2}$ emissions for the baseline (BASE), the default reference case $(40 \% \mathrm{DEF})$, and the default mitigation case $(80 \% \mathrm{DEF})$. One model is not able to reach the $80 \%$ reduction target (see Sec. 3.1). Discrepancies in the base year occur because of slightly different geographical definitions for the EU27 (in some models, EU27 includes countries that are not EU Member States, such as Switzerland and Norway), and because the project does not attempt to harmonize the model data for historical years. The models can, therefore, have different calibrated base years (2005 and 2010 being the most common) and use different variables. 


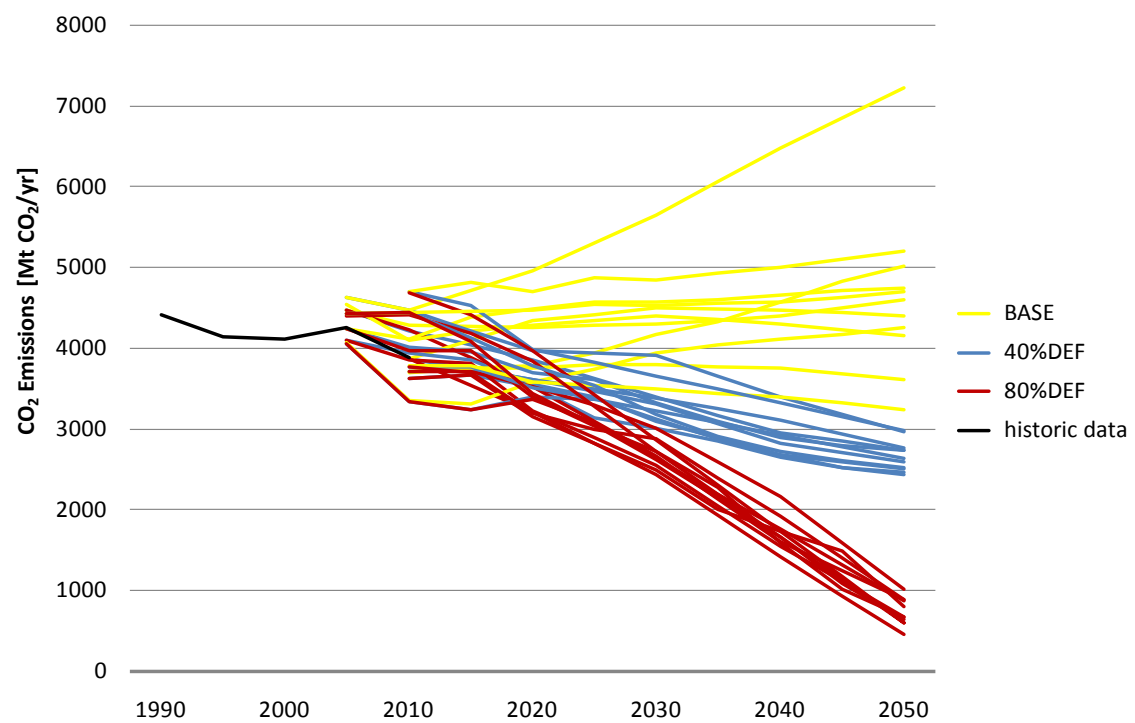

Figure 1. $\mathrm{CO}_{2}$ emissions (excluding land-use) for all models for the baseline BASE, default reference scenario (40\%DEF), and default mitigation scenario (80\%DEF). Historical emissions based on EEA (2012).

Model-specific BASE scenarios show a high degree of variation in terms of $\mathrm{CO}_{2}$ emissions. Historically, there has been a decrease in emissions since 1990 (EEA, 2012), but only TIMES-PanEU shows a continuation of this decrease in the baseline, leading to a greater than $10 \% \mathrm{CO}_{2}$ reduction by 2050 , relative to 2010 . In contrast, two models - EPPA and TIAM-UCL - project a drastic increase in emissions (between $40 \%$ and 60\%, respectively) between 2010 and 2050. All the other models suggest a more modest increase of less than $15 \%$.

In the other two scenarios, the historical trend of decreasing $\mathrm{CO}_{2}$ emissions continues in the EU, leading to at least a $20 \%$ reduction in 2020 , relative to 1990 . The differences between the default reference and the default mitigation case stand out clearly from 2025 onwards. In several models, the default mitigation scenario (80\% DEF) leads to far more substantial reductions in 2020 than that achieved in the default reference scenario (40\%DEF) (Sec. 4). The fact that some models go below the cap by 2020 suggests that the cost of rapid reductions needed to achieve the 2050 target are exceedingly high and, therefore, mitigation begins earlier.

The mean annual $\mathrm{CO}_{2}$ reduction rates for the default reference case are approximately $1 \%$ per year for 2010-2030 and 2030-2050. In the default mitigation scenario, the emission reduction rates increase to $2.2 \%$ and $6.1 \%$ for the first and second period, respectively. This indicates a higher mitigation effort not only in the long-term, but also in the mid-term up to 2030 (Sec. 4). The wide range observed for emission reduction rates reflects the diversity in BASE scenario emissions, which will have implications also in terms of policy costs. By contrast, emissions for the $40 \% \mathrm{DEF}$ and $80 \% \mathrm{DEF}$ scenarios converge by definition, as $40 \%$ resp. $80 \%$ GHG reduction is required by 2050 . Reaching a 


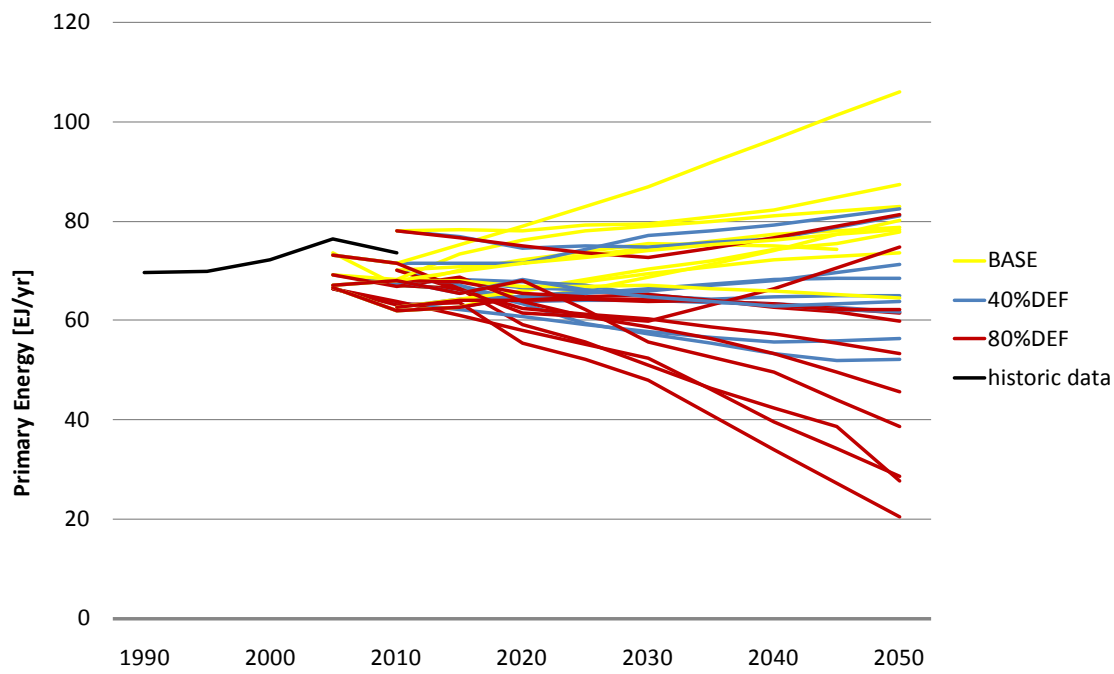

Figure 2. Primary energy use for all models for the baseline scenario BASE, the default reference scenario $40 \% \mathrm{DEF}$, and the default reference scenario $80 \% \mathrm{DEF}$. Historical data based on Eurostat (2012b).

given emission reduction target from a higher BASE trajectory is certainly more challenging than reaching it from a trajectory that is only little above the $40 \%$ reduction line.

The trends in primary energy vary considerably across the models including the $40 \%$ DEF and $80 \%$ DEF scenarios (Fig. 2), indicating that similar emission pathways can be achieved through alternative energy transitions. A first robust tendency observed across the models is the decline in primary energy use in the reference scenario (compared to the baseline) and in the mitigation scenario (compared to the reference case). ${ }^{8}$ The trend in time is more variable. Except for TIMES-PanEU, all the models show either constant or increasing primary energy use in the baseline (BASE). In the default reference case (40\%DEF), nearly half of the models show a moderate increase while the other half show a moderate decrease (with a maximum increase of $15 \%$ for PET and TIAM-UCL, and a maximum decrease of 26\% for EPPA). In the default mitigation case (80\%DEF), one model (TIMES-VTT) suggests an increase in primary energy use, while the others remain more or less at the 2010 level or demonstrate a decrease in their primary energy use (up to 55\% in EPPA, FARM-EU and in this version of PACE).

A second robust finding across the models is that reduction of energy intensity plays an important role in decreasing emissions. Figure 3 plots changes in energy intensity (EI, defined as primary energy over GDP) against changes in carbon intensity (CI, defined as $\mathrm{CO}_{2}$ emissions over primary energy) between 2010 and 2050 for the

\footnotetext{
${ }^{8}$ It should be noted that this finding is also affected by the primary energy accounting method: many carbon free options (i.e., nuclear, nonbiomass, and renewables) lead to a lower primary energy use, while their share increases with mitigation. The same conclusion can be drawn for final energy as the above finding for primary energy use is supported.
} 


\section{B. Knopf et al.}

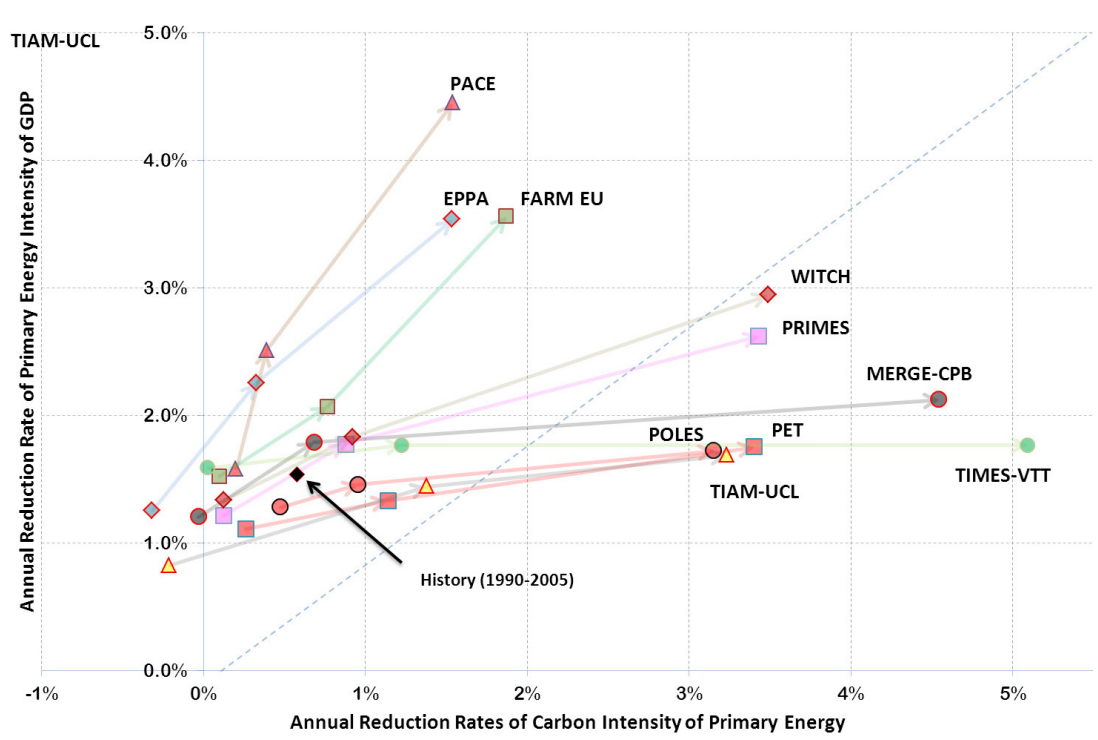

Figure 3. Annual reduction rates of CI and EI between 2010 and 2050 for the baseline (BASE), the default reference $(40 \% \mathrm{DEF})$, and the default mitigation $(80 \% \mathrm{DEF})$ scenarios, represented by the three markers on each line, in the direction of the arrows (from left to right). Historical data are given for annual reduction rates between 1990 and 2005.

baseline, the default reference, and the default mitigation scenario (representing the three markers on each line). The first markers on the left reflect the baseline and indicate that improvements in energy efficiency occur without climate policies. Results are more mixed regarding carbon intensity and in the baseline scenario models, $\mathrm{CI}$ is either increased or slightly decreased. The diagonal line represents the situation in which the reduction rates of energy intensity and carbon intensity are equal. For the BASE scenarios, it can be seen that the reduction of EI has by far the larger impact on emissions (the reduction of CI only plays a limited role). Reduction of CI, however, becomes more important in the $40 \%$ DEF scenario, but all data points remain on the left half of the $45^{\circ}$ line, implying that reduction of EI is the main option.

This changes in the $80 \% \mathrm{DEF}$ scenario. In this scenario, there are two main response strategies across the models. One group of models always chooses EI as the main option, regardless of the stringency of the policy. This cluster of models remain above the $45^{\circ}$ line and primarily includes CGE models (PACE, FARM-EU, and EPPA), which generally have lower potential for substitution across technologies than energy system models. The second group includes models that rely on energy intensity reductions when the emissions target is moderate, but switch to decarbonization as the main strategy given the $80 \%$ emissions reduction target. In this cluster, we find models with a wider portfolio of explicitly carbon-free technologies (e.g., energy system models) or models that endogenously respond to the carbon price signal with induced innovation (WITCH) and technological change driven by learning-by-doing (e.g., WITCH and MERGE-CPB). A similar clustering of models also emerges when 
comparing short- and long-term strategies in the mitigation scenario. CGE models tend to rely on EI in the short- and long-term, whereas the other models switch from EI to decarbonization after 2030 (Förster et al., 2013). For a comprehensive overview of the importance of technological change induced by climate policy and how it is represented in different types of models, see Edenhofer et al. (2006).

All baseline scenarios show a slower improvement of CI than the historical rates of $0.57 \%$ per year from 1990-2005. However, it should be noted that most historic improvements originate from the modernization and restructuring of the Eastern European economies and that more recently, the reduction in CI has not been noteworthy (only 0.19\% p.a. from 2000-2005). In fact, some models show a future increase in CI (TIAMUCL, PACE, EPPA) in the no-policy baseline. The historical trend of $1.5 \%$ for EI reduction from 1990-2005 is projected to continue in the baseline scenarios of most models. Some models show much higher values in the baseline than was observed in the past (e.g., TIMES-VTT, this version of PACE) while others continue the trend (FARMEU, POLES, PRIMES, WITCH) or show a reduction (TIAM-UCL). In the default reference and mitigation scenarios, and in contrast to the baseline scenario, energy efficiency improvement and reduction of CI are as high as historical values. In the default mitigation scenario, these rates are pushed to 3-4\% for EI in the CGE models (EPPA, FARM-EU, and this version PACE) and for CI in the other models (MERGE-CPB, PET, POLES, PRIMES, TIMES-VTT, and WITCH).

\subsection{Identifying technological options for decarbonizing the energy system}

The previous section emphasizes the important role CI reduction plays in most models in the mitigation scenario, as opposed to the reference scenario. In this section, we give a detailed analysis of the decarbonization. First we concentrate on the scenarios BASE, $40 \%$ DEF and $80 \%$ DEF. In Sec. 2.3, we analyze the influence of the different technology variations. Currently, primary energy mix in the EU is dominated by the fossil fuels oil, gas, and coal, providing $35 \%, 25 \%$, and $16 \%$ respectively in 2010 , totaling $76 \%$. Nuclear contributes $14 \%$, while bioenergy and nonbiomass-renewables account for $7 \%$ and $3 \%$, respectively (Eurostat, 2012c).

While there is significant variety across the different models and mitigation scenarios, some robust conclusions about the importance of certain technologies can be identified. In the first period up to 2030, oil and gas remain relatively stable and are similar in all three scenarios. Coal use, in contrast, is reduced considerably by 2030 in $40 \%$ DEF and $80 \%$ DEF compared to the BASE scenario (Fig. 4), while fossil-CCS only has a limited contribution up to 2030. In the second period up to 2050, a greater reduction is observed for oil and gas in $80 \% \mathrm{DEF}$ but not $40 \% \mathrm{DEF}$. In the $80 \% \mathrm{DEF}$ scenario, coal without CCS is almost completely phased out by 2050 , while fossil fuels with CCS (mainly coal and partly gas) contribute substantially to long-term mitigation. By 2050, in a few of the models, fossil-CCS is being used in the default reference scenario $(40 \% \mathrm{DEF})$. 
2030

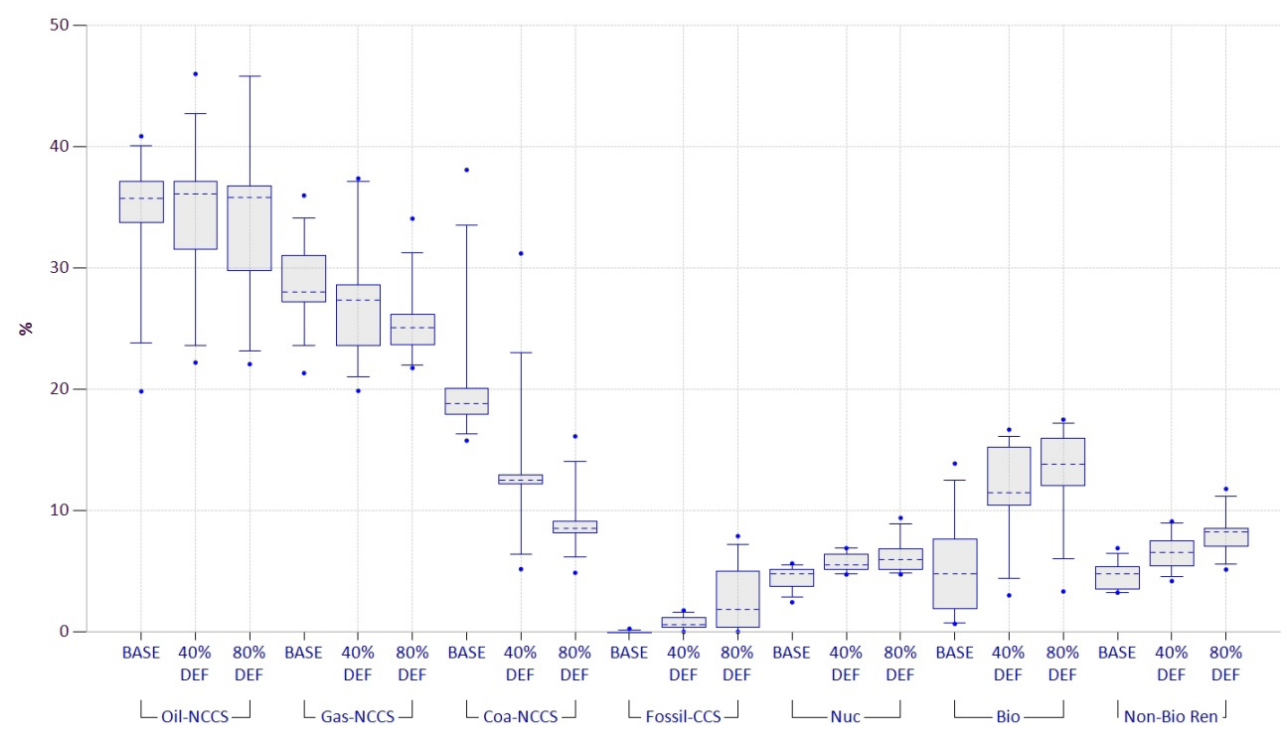

2050

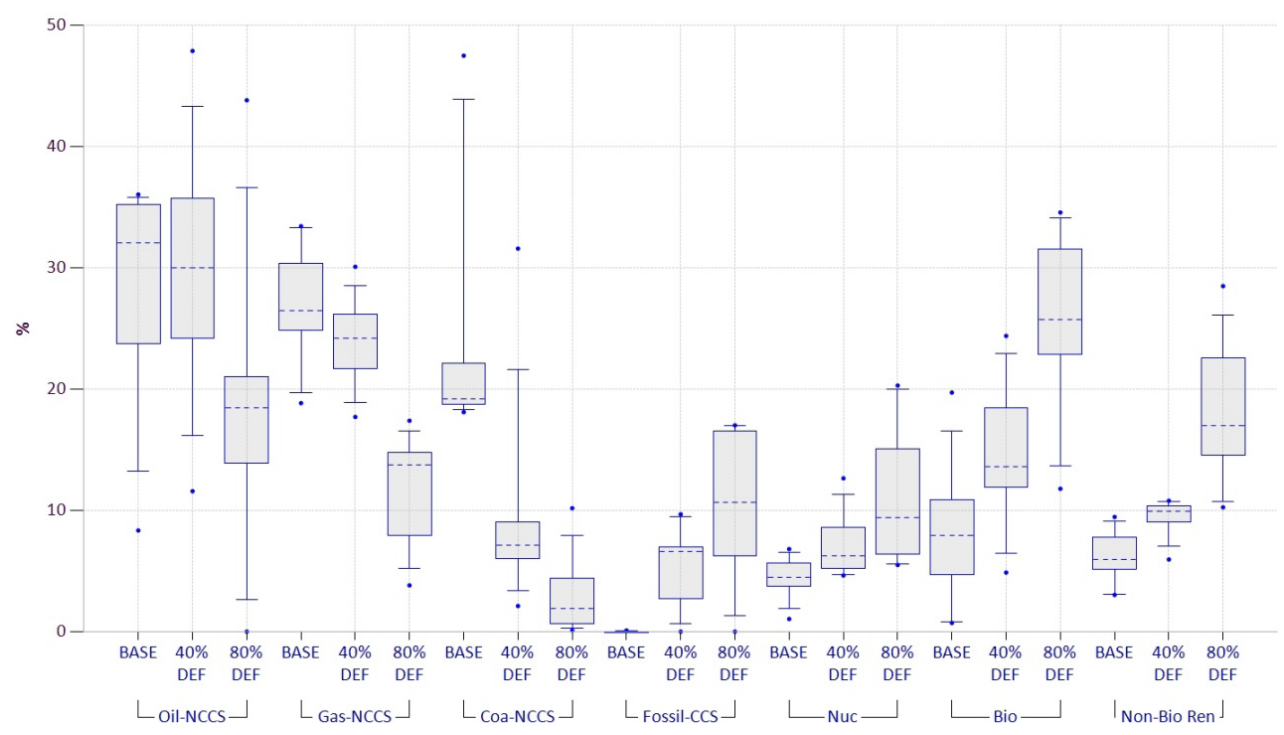

Figure 4. Percentage share of different technologies in primary energy for 2030 (upper panel) and 2050 (lower panel). The dotted line is the median, the box contains the 50\% interval, the whiskers mark the $90 \%$ interval, and the dots mark the extreme values. NCCS: without CCS. Non-Bio Ren: non-biomass renewables. For renewable energies and nuclear energy the direct equivalent method is used. 
Most models follow a similar decarbonization strategy up to 2030 which reflects the robustness of the model results. Divergences become prominent after 2030, particularly concerning the use of bioenergy outside the electricity sector (Sec. 2.4). Furthermore, the differences between the $80 \% \mathrm{DEF}$ and $40 \% \mathrm{DEF}$ scenarios in 2050 confirm the finding of Fig. 3; while for 40\%DEF a mixture of energy efficiency and reduction of carbon intensity is sufficient, a substantial additional effort in reducing carbon intensity by phasing out fossil fuels is required in most of the models to achieve the mitigation target of $80 \% \mathrm{DEF}$.

As the use of fossil fuels decreases, a simultaneous transformation towards low carbon technologies is observed. This is particularly true for bioenergy (with and without CCS), fossil fuels with CCS, nonbiomass-renewables (NBR), and nuclear for primary energy (Fig. 4). Taken together, renewables (including bioenergy and NBR) make up 38\% [36-45\%] (model median and $25-75 \%$ quartiles) ${ }^{9}$ of primary energy use by 2050 for $80 \%$ DEF. They make up 24\% [21-26\%] and 12\% [7-19\%] in the $40 \%$ and the baseline case, respectively.

In 2010 , the share of nuclear energy in primary energy was roughly $5 \%$. In the $40 \%$ DEF scenario, the models are heterogeneous in terms of the deployment of nuclear energy over time, with some models showing an increase and others a decrease. However, in the $80 \%$ DEF scenario, the deployment level of nuclear energy is constant over time or increases slightly. The use of nuclear increases only moderately with the stringency of the mitigation target (except for PRIMES, where the opposite is the case) and the share is similar to that of NBR. It is important to note that some models have implemented constraints on the use of nuclear. ${ }^{10}$ Due to these constraints, little can be said about the long-term relevance of nuclear energy in Europe.

While global modeling studies often suggest that the combination of bioenergy and CCS (BECCS) is important to ensure the $2^{\circ} \mathrm{C}$ target is achieved (Azar et al., 2006; van Vuuren et al., 2007; Edenhofer et al., 2010), this option is of minor importance in the results of the EU models. BECCS is only used in three of the models (POLES, TIMESVTT, and WITCH) in the mitigation scenario where it provides a 9-11\% share by 2050 . The contrast with global studies is likely due to the shorter time horizon of EMF28 and to the low bioenergy potential in Europe, given that bioenergy trade with the rest of the world is constrained by the scenario definition. In fact, in the global and century-long studies BECCS is primarily deployed after 2050 (Klein et al., forthcoming).

A closer look into individual NBR technologies (hydro, wind, and solar PV) suggests that wind energy will become the most important renewable technology (Fig. 5). The median use of solar PV in the default mitigation scenario is lower than that of wind deployment in the baseline scenario. Although solar PV plays a minor role in the

\footnotetext{
${ }^{9}$ In the following, the first number always accounts for the model median and the numbers in brackets account for the $25-75 \%$ quartiles.

${ }^{10}$ Constraints on nuclear energy are modeled differently. Some models have no constraints (the majority), some restrict nuclear to baseline levels (MERGE-CPB), some only implement reactors that are under construction (e.g., EMILIE), and some set a (time-dependent) constraint on the share of nuclear (e.g., PACE, TIAM-UCL).
} 

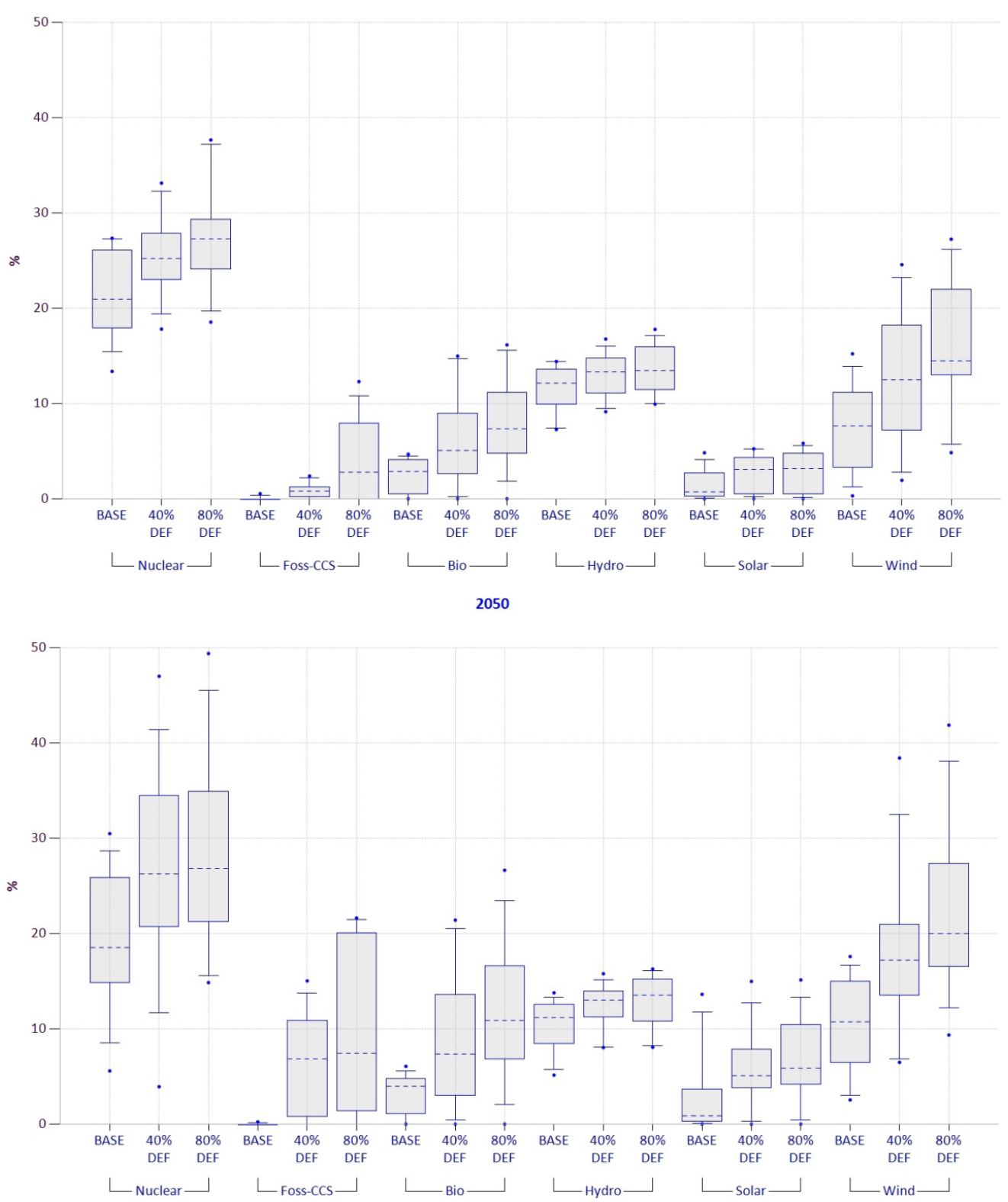

Figure 5. Percentage share of low carbon technologies in electricity mix for 2030 (upper panel) and 2050 (lower panel). The dotted line is the median, the box contains the 50\% interval, the whiskers mark the $90 \%$ interval, and the dots mark the extreme values.

electricity mix for $80 \% \mathrm{DEF}$, it should be noted that other solarthermal technologies contribute significantly to sectors other than electricity in some of the models. Hydro is constant over time because no model assumes new significant capacities. Wind increases considerably over time, with a seven-fold increase at absolute levels (model 
median) from 2010-2050, with PRIMES showing the greatest deployment. Wind power actually reaches a similar deployment level as nuclear energy, with nuclear remaining more or less stable over time (see earlier) and therefore likely to play a similar role by 2050 as nuclear energy does today. Solar PV and wind power collectively account for $27 \%$ [16-38\%] of the $80 \%$ DEF scenario by 2050 , compared to approximately $5 \%$ by 2010 (with solar contributing less than 1\% according to Eurostat (2012a)). Due to the variability of these two technologies, a considerable expansion of the European grid and/or electricity storage options will be required in order to balance the various renewable sources (see Holz and von Hirschhausen (2013)). Most of the models do not consider this factor. In the $40 \% \mathrm{DEF}$ scenario the figures for solar PV and wind power are similarly high with a median of $21 \%$ [12-28\%].

The share of bioenergy in the electricity mix is much lower than in the primary energy mix. Although this is partly due to the primary energy accounting method, it also results from the fact that most of the models use bioenergy in the heating and transport sectors (Sec. 2.4).

\subsection{Influence of technology choices and technology development}

This section analyzes how technology availability and development could influence the EU climate policy (see Sec. 1.2). We focus on those low-carbon technologies that are not constrained by the scenario definition, namely bioenergy, wind and solar (hydro stays more or less constant, see Fig. 5). Figures 6 and 7 give the shares in primary energy for these technologies. As an indicator we use the spread of the model median values between the different technology scenarios. A large spread between different scenarios indicates a high sensitivity to scenario assumptions, rendering policy-making on (renewable) energy policy more difficult. For the effect on the costs see Sec. 3.2.

The first important finding is that emission reduction targets are feasible for all models that provide these scenarios even when constraining CCS availability or nuclear deployment. ${ }^{11}$ The scenarios that exclude CCS show that CCS availability is not pivotalin reaching the mitigation target, provided other options can be substituted. In fact, when CCS is constrained, nuclear deployment is increased. Moreover, higher energy efficiency improvement rates are achieved in these scenarios and primary energy use in absolute terms will be further reduced.

With the exception of the high efficiency scenarios (40\%EFF and $80 \% \mathrm{EFF})$, the default scenarios (DEF) provide the lowest median deployment rates (for bioenergy, solar, and wind). The highest rates are observed in the PESS and the GREEN scenarios because in these cases CCS is not available and nuclear is phased-out, so renewables are the only low-carbon technology option that is left. In the GREEN scenario, this is compensated for by the fact that renewables are either less costly or have a more rapid diffusion compared to the default case, and higher energy efficiency is assumed. But

${ }^{11}$ Note that not all models provide all scenarios. 

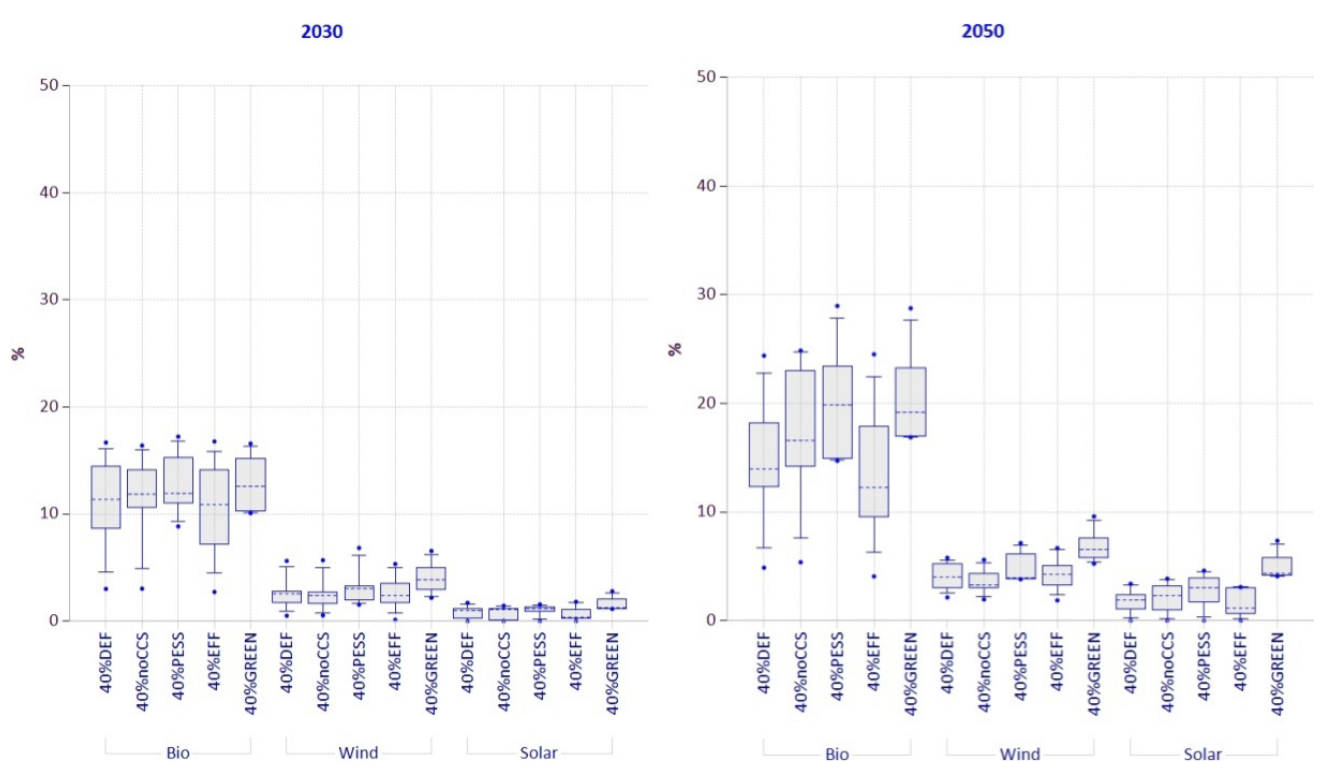

Figure 6. Percentage share of bioenergy, solar, and wind in primary energy for 2030 (left) and 2050 (right) for the $40 \%$ GHG reduction scenarios. The dotted line is the median, the box contains the $50 \%$ interval, the whiskers mark the $90 \%$ interval, and the dots mark the extreme values. Note that only six of the models provide the full set of technology scenarios. Definitions of the technology scenarios are given in Table 1.
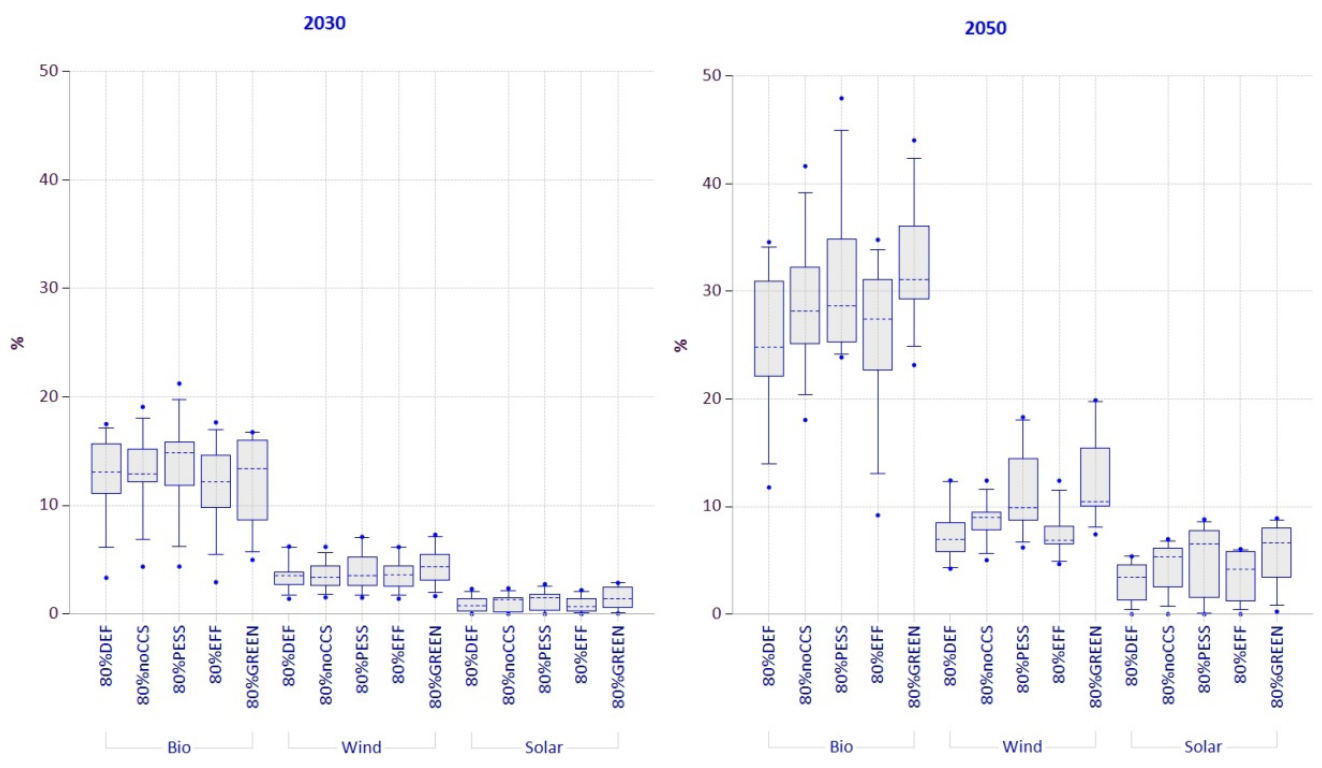

Figure 7. Percentage share of bioenergy, solar, and wind in primary energy for 2030 (left panel) and 2050 (right panel) for the $80 \%$ GHG reduction scenarios. The dotted line is the median, the box contains the $50 \%$ interval, the whiskers mark the $90 \%$ interval, and the dots mark the extreme values. Note that only six of the models provide the full set of technology scenarios. Definitions of the technology scenarios are given in Table 1. 
the GREEN and PESS scenarios remain very similar indicating that simultaneously foregoing both CCS and nuclear might be more important for the development of renewables than any assumptions regarding renewable technology characteristics or energy efficiency. By contrast, the no CCS scenario, where only CCS is constrained, has a smaller influence on the deployment of wind and solar, but a larger influence on nuclear deployment (not shown here).

With high energy efficiency (EFF), the need for deployment of bioenergy, wind and solar slightly decreases, so a lower median value compared to the DEF scenario is observed. For both the $40 \%$ and $80 \%$ reduction scenarios, the differences between the model medians for the technologies for primary energy production, between the scenarios in 2030, are small at less than three percentage points. The spread does not increase with the stringency of the target: model spread for the $40 \%$ and $80 \%$ scenarios are of similar order of magnitude. For 2050, however, the spread increases considerably up to eight (six) percentage points for the $40 \%$ (80\%) scenarios. Although the spread is quite small for primary energy, the effect is much larger in the power sector, where the spread for wind is about nine (six) percentage points by 2030 and as large as $22(17 \%)$ points by 2050 (about 11 (10)\% points for PV) for the $40 \%$ (80\%) scenarios.

The policy implication that can be drawn from the technological sensitivity analysis is twofold. First, until 2030 the spread in results induced by different technology assumptions is small but increases by 2050. Second, both the scenarios that constrain CCS at the same time as nuclear deployment (GREEN and PESS) tend to influence the distribution of model results towards greater deployment of wind and solar PV. This results in considerable uncertainty for the deployment of fluctuating renewables in the power sector and, with it, for electricity grid planning. The development of storage options and better demand-side measures might therefore be important to reduce this uncertainty.

\subsection{Sectoral analysis}

This section examines the details of three end-use sectors and compares their contribution to the mitigation of the electricity sector. As shown in Fig. 8, the electricity sector accounts for more abatement than any other sector (industry, transport, residential and commercial) and is fully decarbonized by 2050 in the default mitigation scenario $(80 \% \mathrm{DEF})$ in all the models. Although the other sectors also contribute to the mitigation effort to achieve the $80 \%$ GHG emissions reduction target, the electricity sector is by far the most important. The results suggest that the mitigation options in the power sector appear rather "early on the marginal abatement cost (MAC) curve." Emission reductions in the electricity sector are achieved through CI reduction rather than through EI improvements. Absolute electricity consumption remains more or less constant throughout the period, even decreasing in the $80 \%$ DEF in 2050. However, between 2010 and 2050, the share of electricity in final energy consumption increases considerably, by $15 \%$ (BASE), 30\% (40\%DEF), and 80\% (80\%DEF), pointing to the importance of electrification in the future energy system. 

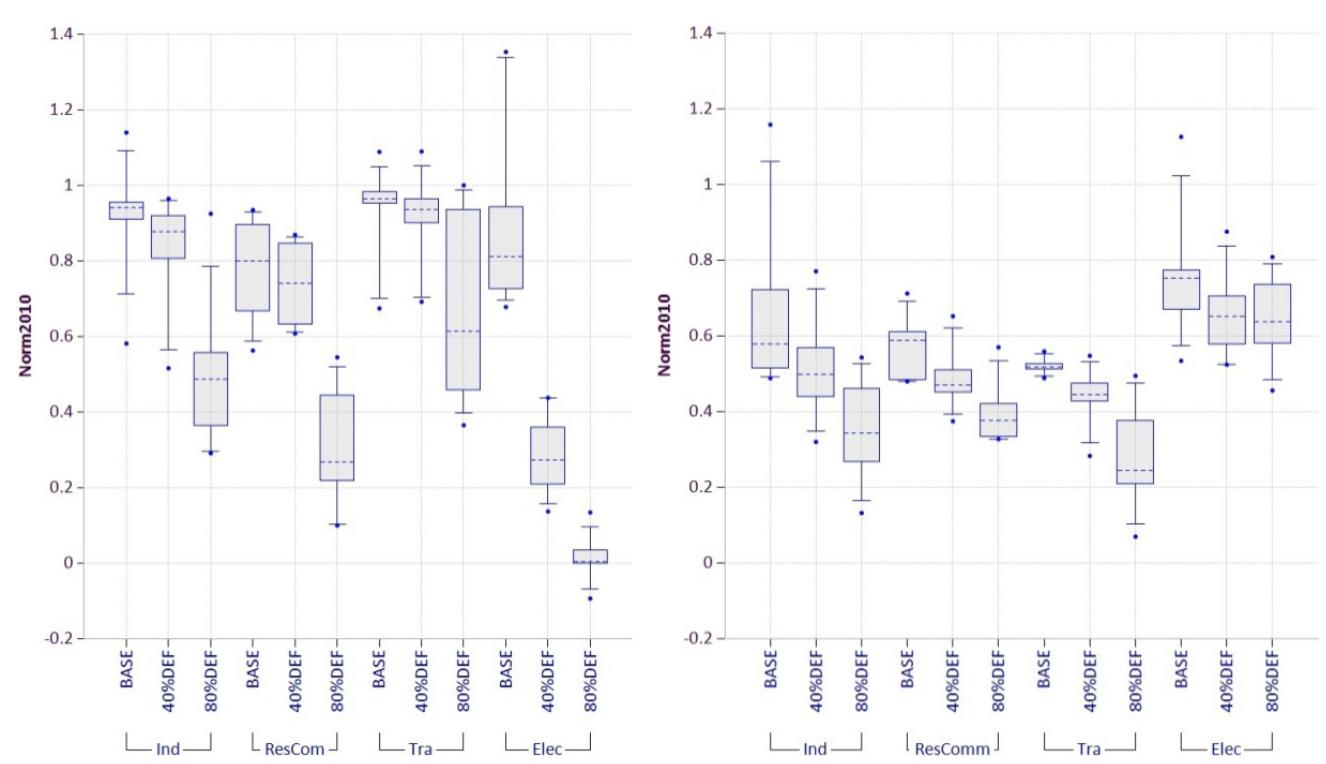

Figure 8. Sectoral analysis of reduction in CI (left) and final EI (right) indexed to one in 2010 for the different sectors (industrial, residential and commercial, transport, and electricity). The carbon intensity of each sector is shown in the left chart and the sector energy intensity in terms of GDP in the right chart. The 2010-2050 growth rates normalized to 1 in 2010 are shown for the baseline (BASE), the default reference $(40 \% \mathrm{DEF})$, and the default mitigation scenario $(80 \%$ DEF).

In contrast to the electricity sector, EI reduction is the dominant result of carbon mitigation policies for the other sectors (industrial, residential and commercial, and transport). Figure 8 shows that CI will only marginally improve in the $40 \% \mathrm{DEF}$ scenario showing a greater improvement in the $80 \% \mathrm{DEF}$ scenario. It seems that the transport sector is the most costly to decarbonize, as reductions in CI can only be achieved with the high $\mathrm{CO}_{2}$ prices found in the $80 \% \mathrm{DEF}$ scenario. This may lead to the conclusion that this sector is indeed the most difficult to decarbonize, especially given the recent rapid increase in transport emissions. The results from PRIMES are an exception in this area, cutting a higher level of emissions than the other models. There seems to be some potential for $\mathrm{CO}_{2}$ reduction in the residential and commercial sectors, but realizing this potential requires high $\mathrm{CO}_{2}$ prices. All the models use less coal and more electricity in industrial sectors with carbon mitigation. Similarly the use of gas reduces in the residential and commercial sectors, especially under more stringent mitigation targets. Interestingly, for the transportation sector, which has a $\mathrm{CO}_{2}$ mitigation target, not all the models require a decrease in the use of liquid fuels, especially under a less stringent $\mathrm{CO}_{2}$ mitigation target. The electrification of the transport sector only becomes significant under more stringent mitigation targets.

To summarize, the analysis of sector-specific strategies shows that the electricity sector achieves greater emissions reductions than any other sector and will, at the same time, increase in importance through the electrification of other sectors. Therefore, as 
mitigation targets become more stringent, cutting emissions of the nonelectricity sectors becomes particularly important. Emission reductions in the industrial, residential, and commercial sectors are equivalent; however, the models suggest that the transportation sector is the costliest to decarbonize.

\section{EU Decarbonization Strategies - Feasibility and Costs}

In this section, we explore the feasibility of the EU's decarbonization strategies by investigating the emission prices and economic costs measured in terms of reduction of GDP or consumption. Emission prices are indicators of the relative scarcity of emission allowances and therefore of the stringency of the mitigation challenge. GDP and consumption losses are indicators of economic costs (see Paltsev and Capros (2013) for a discussion on costs concepts and metrics).

\subsection{The level of ambition}

Although all the models - with the exception of TIAM-UCL - find a feasible solution for the ambitious default mitigation scenario (80\%DEF), this does not necessarily mean that this level of ambition is "feasible" in reality. In mathematical terms, "model infeasibility" means that under the given assumptions, the model finds it difficult to fulfill all the constraints it faces simultaneously (e.g., energy demands, environmental targets, resource potentials, maximum speed of technology diffusion, etc.). If any result can be retrieved at all, this is often reflected by a high price for emission certificates and energy. Furthermore, implementing stringent emissions reduction targets requires several additional processes that are not explicitly captured by the simplified tools used in this study, such as successfully completing complex political processes and overcoming the inertia of social and behavioral change (Knopf et al., 2010). At the same time, the models implement a specific set of technologies that can alter feasibility conclusions. For example, the $80 \% \mathrm{DEF}$ scenario is infeasible for TIAM-UCL, but when the scenario is rerun with the possibility of biofuel trade, it is not only feasible, but resulting emissions prices remain well below the median prices of the other models. Furthermore, changes in the feasibility domain can be achieved by altering the binding constraints that prevent the model from reaching lower targets. Therefore, "model (in)feasibility" is a function of a set of reasonable, but limited and highly uncertain model assumptions. This indicates that models may, at best, provide information about the feasibility of the mechanisms that the model is able to capture (i.e., the technical and economic dimensions of feasibility). Real world interpretation of the results should always be very cautious as conclusions regarding feasibility are not easily transferable to the real world.

Marginal abatement costs or carbon prices (such as for emissions certificates) in stringent mitigation scenarios may be used as an indicator of the level of constraint under which the models operate (Fig. 9). In the default reference case (40\%DEF), carbon prices increase over time to a median value of $64 € / \mathrm{tCO}_{2}\left[48-83 € / \mathrm{tCO}_{2}\right]$ in 2050. 


\section{B. Knopf et al.}
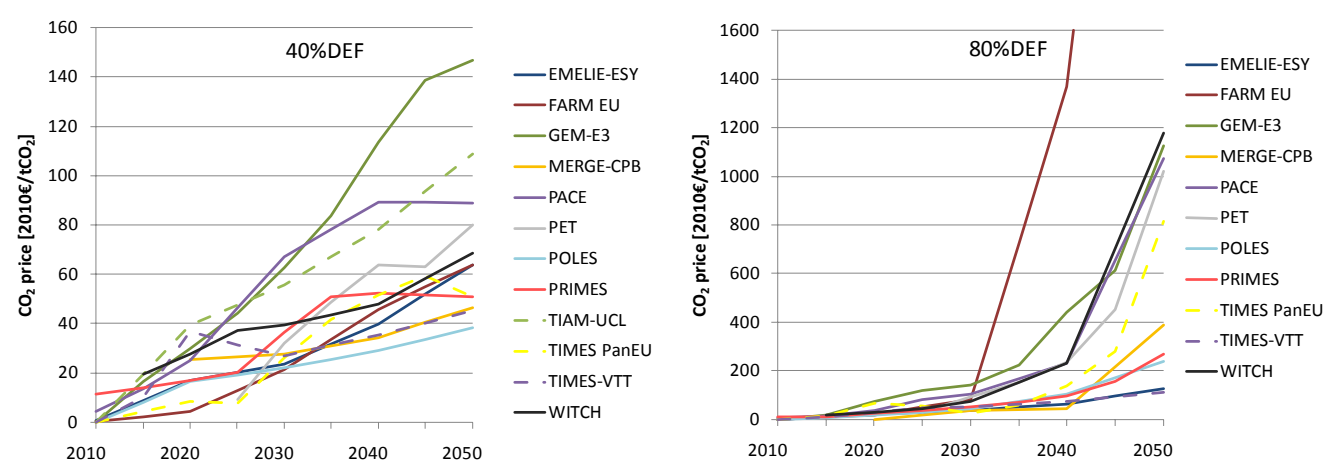

Figure 9. $\mathrm{CO}_{2}$ prices for the default reference scenario $40 \% \mathrm{DEF}$ (left) and the default mitigation scenario $80 \% \mathrm{DEF}$ (right). Note the different scales (factor of 10 between $40 \% \mathrm{DEF}$ and $80 \% \mathrm{DEF})$.

This increase is rather linear. It is also completely different from the default mitigation scenario $(80 \% \mathrm{DEF})$ where carbon prices are not only much higher, but also show a sudden increase after 2040 in some of the models. This leads to a median value of 521 $€ / \mathrm{tCO}_{2}\left[240-1127 € / \mathrm{tCO}_{2}\right]$ by 2050 (compared with $76 € / \mathrm{tCO}_{2}\left[61-169 € / \mathrm{tCO}_{2}\right]$ in 2030), at which point the models have already utilized most of their (cheaper) mitigation possibilities under the given constraints.

Specifically, CGE models (FARM-EU, ${ }^{12}$ GEM-E3, ${ }^{13}$ and PACE) show the highest $\mathrm{CO}_{2}$ prices in 2050 , mainly due to the way technological mitigation possibilities enter these models. It is likely that structural breaks will be necessary for stringent mitigation scenarios to become feasible, i.e., new technologies will enter markets that have different input structures than the technologies available today. CGE models are calibrated against baseline data from a single point in time (in which only a limited set of technologies is available) and mostly model anomalies from this point onwards. The use of constant elasticity of substitution (CES) production functions to describe substitution possibilities between sectors, production inputs and technologies, and the use of supply elasticities of technologies for electricity generation, particularly limits the degree of flexibility. This flexibility is lower than that of energy system models with greater substitution possibilities. The WITCH model, which also characterizes production and substitution via CES functions, shows a relatively high $\mathrm{CO}_{2}$ price, closer to that of CGE models. In contrast, some models (TIMES-VTT, PRIMES, EMILIE, and POLES) show a smoother increase of $\mathrm{CO}_{2}$ prices in $80 \%$ DEF. These models include a wider range of technological options for the energy sector as well as the mitigation of all GHG gases in energy production and end use sectors, and/or

\footnotetext{
${ }^{12}$ FARM EU currently exhibits high emissions certificate prices in stringent mitigation scenarios due to ongoing development targeted at innovative technologies, such as electricity generation from biomass with CCS and e-mobility, as well as improving the nesting structure of the electricity sector.

${ }^{13}$ In GEM-E3, the result is driven by the endogenous labor-leisure choice. Increasing prices lead to higher costs of the consumption bundle. Households finance this extra cost by increasing labor and decreasing leisure. This means that consumption value is increasing rather than consumption volume.
} 
cross-border commodity trading, which increases flexibility. In the following, we will discuss the costs of the EU's decarbonization policies.

\subsection{Costs of $\boldsymbol{E} U$ decarbonization}

There are different approaches for calculating mitigation costs. Paltsev and Capros (2013) consider the cost concepts used to assess carbon policies in different types of models including changes in GDP, changes in consumption, changes in welfare, energy system costs, and the area under the MAC curve. This section concentrates on the reduction of GDP in the mitigation scenarios and only briefly mentions other cost measures. The exercise therefore only considers the subset of models for which GDP is an endogenous variable.

Figure 10 presents the GDP reduction in the reference scenario $(40 \% \mathrm{DEF})$ compared to the no-policy baseline (BASE) and of the mitigation scenario $(80 \% \mathrm{DEF})$ compared to the reference scenario $(40 \% \mathrm{DEF})$. In the reference scenario, GDP reductions are $0.9 \%[0.4-1.8 \%]$ by 2050 , and the picture resembles the carbon prices discussed in Sec. 2.4: GDP reductions are moderate and below 0.7\% until 2030 and below $2.3 \%$ for 2040. However, after 2040, several models show steep, nonlinear increases in costs up to $10 \%$ (model median $3.7 \%$ ). It is important to note that $80 \%$ $\mathrm{DEF}$ is the scenario that is most restricted in terms of global participation and costs can be decreased considerably if global climate action and international emission trading is assumed (see below). In general, the strong increase in costs for the period 2040-2050 is an indication that the models might miss innovation possibilities in the energy sector, especially in the demand side, that could occur with high energy prices.

In the CGE models (EPPA and FARM-EU), the costs are particularly high in 2050, reflecting fewer abatement options compared to those in the optimization models (e.g., MERGE-CPB). The higher costs in the CGE models could also be due to their recursive mode and the assumption that future policy changes cannot be perfectly anticipated as in the optimization models. Therefore, the models greatly diverge on the costs of the "last
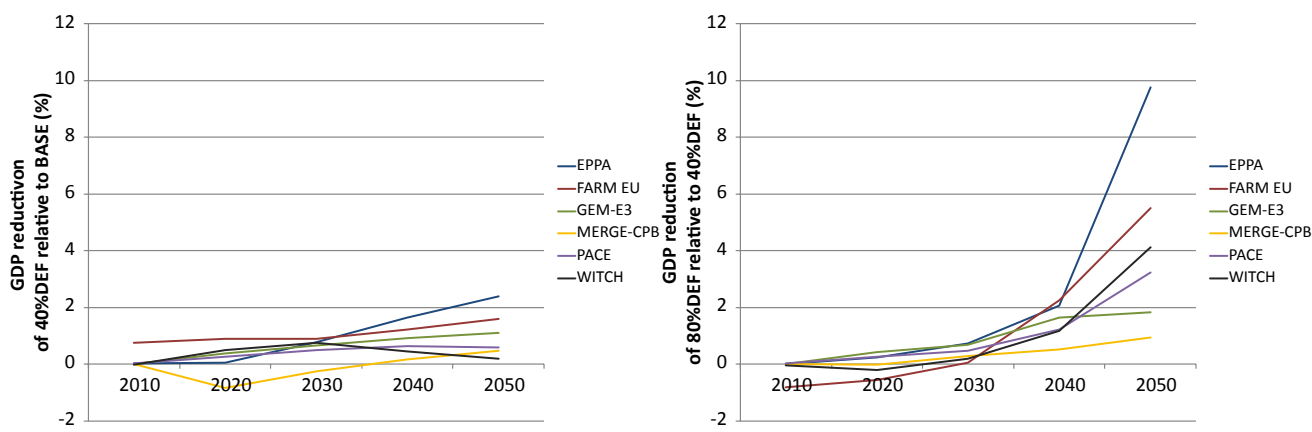

Figure 10. GDP reduction as a percentage of the reference scenario $(40 \% \mathrm{DEF})$ relative to the no-policy baseline (BASE; left) and of the default mitigation scenario $(80 \% \mathrm{DEF})$ relative to the default reference scenario (40\%DEF; right). 


\section{B. Knopf et al.}

mile"; some models suggest that abating the last ton of $\mathrm{CO}_{2}$ could become very costly. The higher costs in EPPA can be explained by (i) the assumption of higher costs of renewables, (ii) the costs for balancing intermittency, and (iii) the built-in model constraints in the penetration of technologies in future periods. FARM-EU shows small GDP gains up to 2030 in the $80 \%$ DEF scenario compared to $40 \%$ DEF. This is because slightly higher targets in $80 \%$ DEF in early years induce structural effects which cause a shift away from energy-intensive production to higher value added nonenergy intensive production. In addition, exports are higher in earlier years. Over time, however, GDP decreases when targets become more restrictive. MERGE-CPB also shows some GDP gains for the 40\% $\mathrm{DEF}$ scenario. In this case, the worldwide moderate climate policy in the $40 \% \mathrm{DEF}$ scenario gives rise to lower international energy supply prices. In regions such as Europe with considerable taxes on fossil fuels the decline in supply prices of fossil energy lowers the expenses on fossil energy, and thus has a positive impact on GDP.

This exercise assumes that the $80 \%$ GHG reduction target will be delivered domestically; therefore, no emissions trading with other world regions is considered. De Cian et al. (2013) analyze the effects of international emissions trading, as described in $80 \%$ GLOB scenario, demonstrating that costs can be reduced significantly when international mitigation potentials are taken into account. If global participation and global emission trading is assumed, $\mathrm{CO}_{2}$ prices decrease considerably and reduce for example by $90 \%$ for FARM-EU to $400 € / \mathrm{tCO}_{2}$, and by $80 \%$ to $233 € / \mathrm{tCO}_{2}$ for WITCH in 2050 for the scenario $80 \%$ GLOB (c.f. Fig. 9). GDP reduction also decreases, for example for EPPA, from $10 \%$ for $80 \% \mathrm{DEF}$ (see Fig. 10) to $5 \%$ for $80 \%$ FRAG with comparable mitigation efforts in other countries, to only $2.8 \%$ under a fully global carbon market in the $80 \%$ GLOB scenario ${ }^{14}$ (always compared to $40 \% \mathrm{DEF}$ ). For further details, for example on the influence of global climate policy regime on trade patterns, technology, and innovation, see De Cian et al. (2013).

Figure 11 presents the impacts of technology assumptions on mitigation costs. The GDP reduction for $80 \% \mathrm{DEF}$ is compared to the costs of the different technology scenarios (Table 1 and Sec. 2.3). For each scenario, the GDP reduction is compared to its associated reference scenario (e.g., $80 \% \mathrm{EFF}$ relative to $40 \% \mathrm{EFF}$; $80 \% \mathrm{PESS}$ relative to $40 \% \mathrm{PESS}$, etc). Technology variation influences mitigation costs, but the overall effect is not very large. Costs tend to increase without CCS availability (80\%noCCS), particularly in the most pessimistic scenario where nuclear is also phased out $(80 \%$ PESS). ${ }^{15}$ Optimistic assumptions on energy efficiency (80\%EFF) cause costs to decrease as high energy efficiency is not available in the DEF scenario, and therefore reduces costs. This effect is also important in the green scenario (80\%GREEN), where the cost increase due to pessimistic assumptions about CCS and nuclear availability

\footnotetext{
${ }^{14}$ In the scenario $80 \%$ GLOB, however, the EU generally achieves emission reduction lower than $80 \%$ by 2050 and will become a net buyer of emission certificates.

${ }^{15}$ Note that in MERGE-CPB, consumption (and not GDP) is optimized. This explains the effect that GDP reduction is slightly lower for the PESS scenario compared to DEF in 2050 as more investments are stimulated in the former scenario. Consumption losses for PESS are clearly higher when compared to DEF.
} 

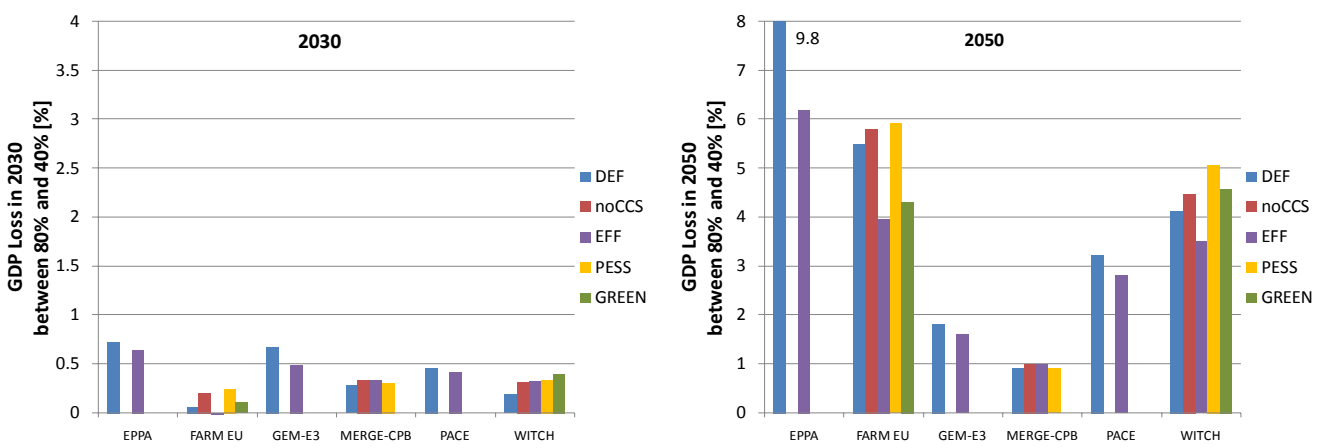

Figure 11. GDP losses for the $80 \%$ DEF scenario and $80 \%$ technology scenarios (relative to their respective reference cases) in 2030 (left) and 2050 (right). Losses are given in that specific year, not aggregated over time. Note the different scales.

can be partly counter balanced by more optimistic assumptions about higher energy efficiency and a more rapid technology development for renewable energy. In general, the differences across the models tend to be larger than the influence of different technological variations on the costs.

GDP loss is only one measure of costs, but these conclusions also hold for the analysis of consumption loss and additional total energy system costs. The same set of models that provides GDP also provides consumption as an endogenous variable. Reduction of consumption for $80 \% \mathrm{DEF}$, when compared to $40 \% \mathrm{DEF}$, follows a very similar pattern as the GDP reduction in Fig. 10, and has a similar order of magnitude (values for 2050 range from $-2 \%$ to $9.5 \%$ reduction). One notable exception is GEM-E3 showing consumption gains over the whole time horizon. In TIMES-PanEU, additional total energy system costs increase from $€ 4$ bn in 2020 and $€ 17$ bn in 2030 to $€ 110$ bn in 2050, again showing a nonlinear increase beyond 2030. Only POLES, providing abatement costs (area under the MAC curve), shows a more linear increase. Other types of costs, for example, costs from an end-user perspective, are not considered in this exercise. Paltsev and Capros (2013) provide a more detailed analysis of the costs of European mitigation. However, it is necessary to note that although we analyzed the technology cases with constrained availability of technology, the costs do not fully consider real world constraints such as lack of public acceptance for CCS, integration costs for intermittent renewable energy, logistical and infrastructure bottlenecks, sustainability of bioenergy, and insurance costs for nuclear.

\section{Targets and Timing -2020 and Beyond}

The EU has currently fixed targets until 2020 laid out in its 20-20-20 strategy (see Sec. 1.1). Moreover, in 2013 the EU Commission started the discussion about policy targets for 2030. The green paper "A 2030 framework for climate and energy policies" (European Commission, 2013a), assesses the 20-20-20 targets and presents potential 


\section{B. Knopf et al.}

architectures for a post-2020 framework. The document states that there is "broad consensus [...] for interim targets for GHG emissions reductions [...] to reach the aspiration of an $80-95 \%$ reduction by 2050 ". At the same time, it states, "a 2030 target for renewables would have to be carefully considered". Therefore, it is not clear whether the trilogy of GHG reduction, renewable target, and energy efficiency will continue. The document mentions some indicative numbers for potential targets that refer to the EU Energy Roadmap. First that "by 2030 GHG emissions would need to be reduced by $40 \%$ in the EU to be on track to reach a GHG reduction of between $80 \%$ and $95 \%$ by 2050 " and second that "for renewables, the policy scenarios in the Energy Roadmap 2050 indicate a share of around 30\% in 2030" (European Commission, 2013a).

Our model analysis can contribute to this debate by analyzing the two key questions: (i) how do the 2020 targets and long-term goal of $80 \%$ GHG reduction by 2050 relate to each other, and (ii) whether specific conclusions for the pathways and timing of action for 2030 can be surmised from our analysis. To answer these questions, we begin by looking at the EU 20-20-20 targets for emission reductions, renewable deployment, and the indicative target for energy efficiency. We also give indications for potential targets for 2030 for emission reductions and renewable deployment. It should be noted that in our exercise we only consider the climate externality. We include no other public policy objectives, such as employment effects or energy import independence, that might be important in the context of renewable energy deployment (see e.g., Edenhofer et al. (forthcoming)). Moreover, in some cases, the model results cannot be directly compared with these specific targets, either due to limitations in the details of the model's output or different regional aggregation.

\subsection{GHG reduction}

The analysis compares the current 2020 policies to a pathway that aims to reduce GHG emissions by $80 \%$ by 2050 and determines the level of emission reduction required for 2030. The GHG emission reduction targets for 2020 are given as a minimum constraint in all the models (see Sec. 1.2). Since GHG emissions are not reported in all the models, we focus here on $\mathrm{CO}_{2}$ emissions.

Figure 12 shows that in 2020, there is a considerable difference in $\mathrm{CO}_{2}$ emission reduction between the default reference scenario $(40 \% \mathrm{DEF})$ and the "optimal model responses" in the default mitigation scenario $(80 \% \mathrm{DEF})$. This is already the case from 2015 and even more evident from 2020 onwards. The $80 \%$ DEF scenario requires $28 \%$ [26-30\%] $\mathrm{CO}_{2}$ reduction by $2020^{16}$; this is a difference of about seven percentage points in 2020 compared to the $40 \%$ DEF scenario with $21 \%$ [19-25\%]. In other words, the level of effort of $20 \%$ GHG reduction that is included in the default reference scenario $(40 \% \mathrm{DEF})$ up to 2020 is not consistent with the least-cost pathways towards the $80 \%$ reduction target in 2050 . This supports the finding of the "Low Carbon

${ }^{16}$ We take into account $13 \% \mathrm{CO}_{2}$ reduction between 1990 and 2010. 


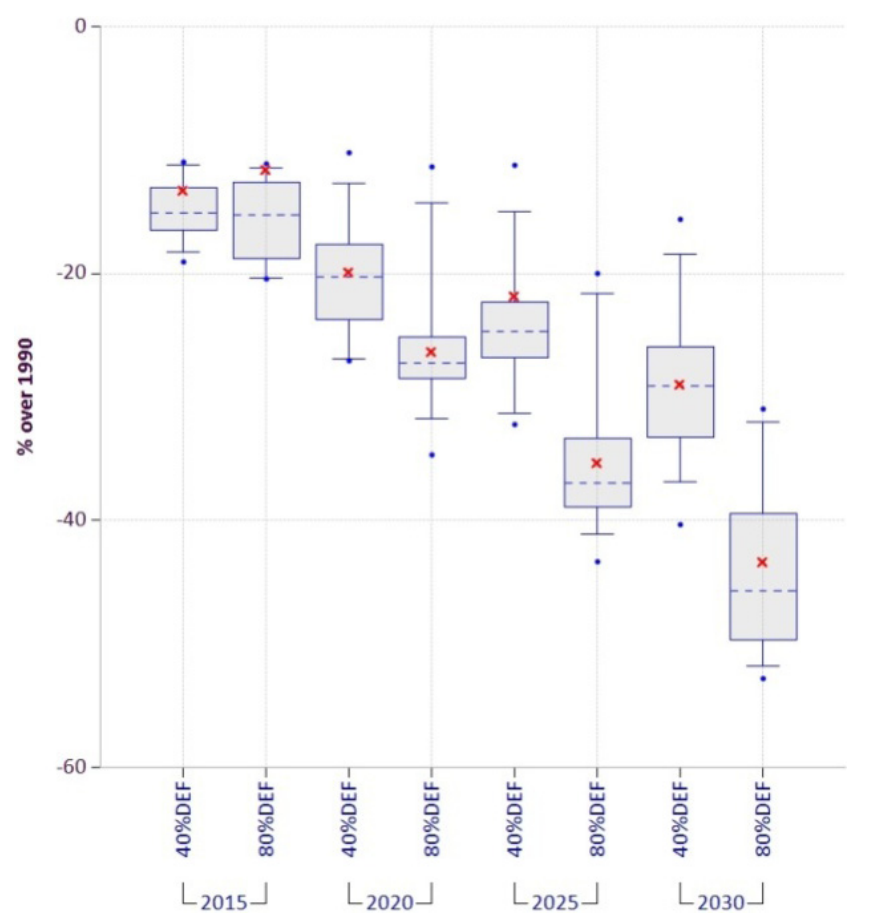

Figure 12. $\mathrm{CO}_{2}$ emissions reductions for different years for $80 \% \mathrm{DEF}$ and $40 \% \mathrm{DEF}$. Historic decreases in $\mathrm{CO}_{2}$ emissions of $13 \%$ between 1990 and 2010 (EEA, 2012), are combined with model-based results after 2010. The crosses mark the values for PRIMES.

Economy Roadmap" (European Commission, 2011d) which points out that a reduction of $25 \%$ by 2020 would be more in line with ambitious long-term targets.

For 2030, the results of this study can be directly compared to the results of the Energy Roadmap. The Energy Roadmap indicates that "in 2030, energy-related $\mathrm{CO}_{2}$ emissions are between $38 \%$ and $41 \%$ lower (compared to 1990), and total GHG emissions reductions are lower by $40-42 \%$." The results from our exercise suggest a $\mathrm{CO}_{2}$ reduction of $47 \%$ [40-51\%] for the default mitigation scenario (80\%DEF), compared to 1990, i.e., a much stronger $\mathrm{CO}_{2}$ reduction than in the Energy Roadmap. This indicates that a reduction of GHG emissions of $40 \%$ by 2030 - as mentioned in the EU green paper (European Commission, 2013a) - could, in principle, be in line with the long-term effort to reduce emissions by $80 \%$. The model median, however, would suggest setting a more ambitious target.

The annual $\mathrm{CO}_{2}$ reduction rates for $80 \% \mathrm{DEF}$ are $2.2 \%$ [1.7-2.4\%] between 2010 and 2030 and $4 \%$ [3.5-4.7\%] between 2010 and 2050 and for the ETS sector the $\mathrm{CO}_{2}$ reduction factor is $5.4 \%$ [4.4-5.9\%] between 2020 and 2050. These rates are clearly above the linear annual reduction factor of $1.74 \%$ that is currently set for the 3rd phase of the EU emissions trading scheme (2013-2020) and beyond 2020. There may be many reasons why short-term constraints make it impossible to follow the pathways of the cost-optimal $80 \%$ DEF scenarios for 2020 or 2030 — but it should be noted that 


\section{B. Knopf et al.}

any short-term delays must be compensated for in the long-term. In the extension of the 2020 target, the policies in the default reference scenario lead to a $40 \% \mathrm{GHG}$ reduction by 2050 . Global studies (e.g., Luderer et al., forthcoming) have shown that similar worldwide policies of only moderate mitigation could lead to a global "muddling through" scenario, with a global average temperature increase of approximately $3-4^{\circ} \mathrm{C}$ in 2100 , which is considerably higher than the targeted increase of a $2{ }^{\circ} \mathrm{C}$ maximum.

\subsection{Renewable energy}

In terms of the second component of the EU 20-20-20 policy - renewable deployment - the target has been formulated in such a complex way that it is difficult to track based on the variables and accounting, e.g., of bioenergy, reported by the models. One commonly used proxy for renewable deployment is the share of renewable energy in the electricity mix and primary energy (Figs. 13 and 14). Interestingly, the difference in renewable deployment in the electricity sector between $40 \%$ DEF and $80 \%$ DEF is not significant based on the models' means, although the spread within the $80 \%$ DEF scenario extends somewhat higher (Fig. 13; Sec. 2.4), especially towards 2050. On average, the deployment of RES shows a steady increase up to 2050 . However, saturation can be noted in some models after 2030 as it becomes more

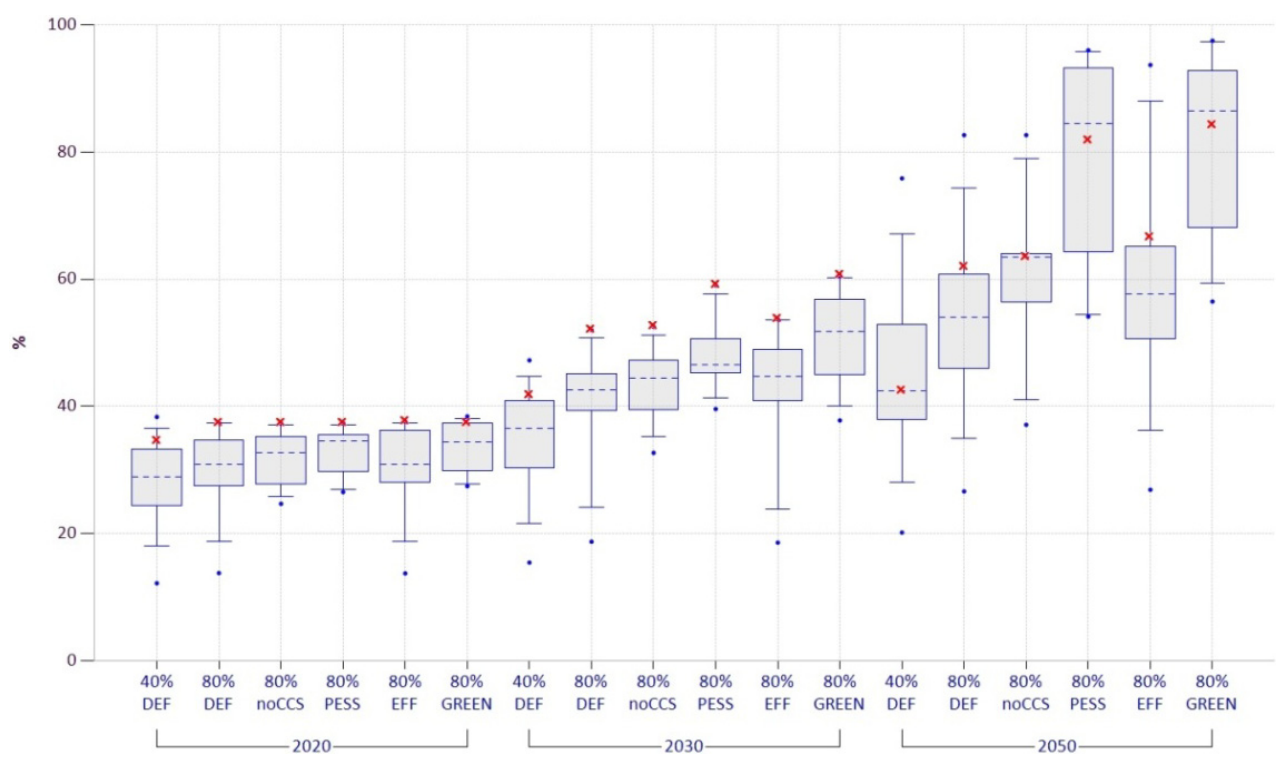

Figure 13. Share of renewable energy sources (RES) in total electricity generation for different years. The dotted line is the median, the box contains the $50 \%$ interval, the whiskers mark the $90 \%$ interval, and the dots mark the extreme values. Note that not all the models provide all technology scenarios; therefore, in these scenarios the set of models is smaller than for $40 \%$ DEF and $80 \%$ DEF. The crosses mark the values for the PRIMES model. 


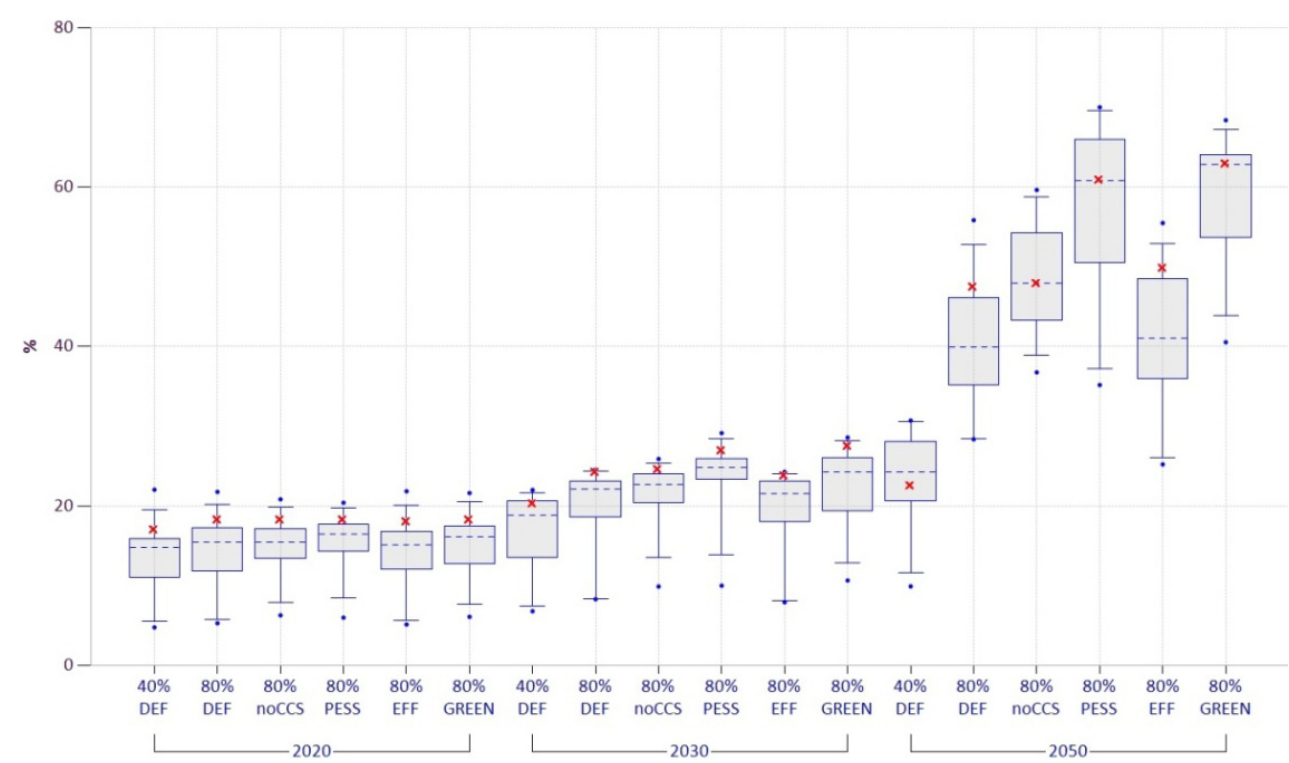

Figure 14. Share of Renewables (NBR+Bio) in total primary energy. The dotted line is the median, the box contains the $50 \%$ interval, the whiskers mark the $90 \%$ interval, and the dots mark the extreme values. Note that not all the models provide all technology scenarios; therefore, in these scenarios the set of models is smaller than for $40 \% \mathrm{DEF}$ and $80 \% \mathrm{DEF}$. The crosses mark the values for the PRIMES model.

important to utilize bioenergy to decarbonize sectors other than electricity. To obtain an indicative number of the share of renewables in the electricity sector that would be consistent with the overall renewable target, the document "Renewable Energy: Progressing towards the 2020 target" (European Commission, 2012) states that renewable energy should constitute 37\% of Europe's electricity mix by 2020. Clearly, a 37\% share is at the upper limit of what the models report for 2020 . One reason might be, as stated above, that there are reasons other than GHG reduction for the deployment of renewables, and that these are not being captured by the models. In this respect, it is also important to note that the recent "Renewable energy progress report" (European Commission, 2013b) states that the 2020 renewable target might not be met and that more effort is needed to reach it, implying that the $20 \%$ renewables target might indeed be very ambitious.

Figure 14 presents the share of renewables in total primary energy. This graph shows a considerable increase in the share of renewables over the entire 2010-2050 period. Furthermore, a clear increase between the default reference $(40 \% \mathrm{DEF})$ and the default mitigation scenario $(80 \% \mathrm{DEF})$ can be noted for 2050 . This increase is mainly due to the increase in bioenergy after 2030.

Interestingly, the models reveal a significant change in the pattern and extent of the share of RES in relation to electricity generation and primary energy from 2020-2030 and further to 2050. Although the shares of RES are rather homogenous across models 


\section{B. Knopf et al.}

and technology scenarios in 2020 , the picture changes in 2030, which demonstrates the increasing importance of RES and more divergent patterns across technology scenarios. By 2030, the share of RES is much higher in the mitigation cases where CCS is not allowed (80\%noCCS and 80\%GREEN) and nuclear deployment is low (80\%PESS and $80 \%$ GREEN) and where additionally the assumptions on energy efficiency and renewable deployment are optimistic (80\%GREEN). The share of RES in electricity generation reaches $47 \%$ (for $80 \%$ PESS) and $55 \%$ (for $80 \%$ GREEN), compared to $41 \%$ for $80 \% \mathrm{DEF}$. This effect is even stronger by 2050 , as the share of RES reaches a median value of approximately $85 \%$ for $80 \%$ PESS and $80 \%$ GREEN, compared to $48 \%$ in the default mitigation scenario, $80 \% \mathrm{DEF}$.

Concerning the implication for a potential renewable target for 2030, it is important to note that over time the share of renewables continues to increase in all models demonstrating the importance of renewables (mainly bioenergy) for long-term energy transformation. In addition, based on the analysis in Secs. 2.1 and 2.2, the model results suggest that wind could become of considerable importance and be promoted based on its expected long-term potential.

\subsection{Energy efficiency}

The third important point of the 20-20-20 targets relates to energy efficiency. The Directive 2012/27/EU on energy efficiency, ${ }^{17}$ adopted in October 2012, states that a cumulative end-use energy savings target must be achieved by 2020: "That target shall be at least equivalent to achieving new savings each year from 1 January 2014 to 31 December 2020 of $1.5 \%$ of the annual energy sales to final customers of all energy distributors" (European Parliament and the European Council, 2012, Art.7). Because of several amendments and exceptions, this target cannot be directly compared to the model results, but at least it is clear that an absolute reduction in final energy use is intended.

All the models reveal a considerable reduction of EI with a model median of $1.8 \%$ [1.5-2.1\%] p.a. in the default reference scenario (40\%DEF) and 2.1\% [1.7-3.5\%] p.a. in the default mitigation scenario (80\%DEF; Fig. 3) between 2010 and 2050. For the $80 \%$ DEF scenario, even a reduction in absolute final energy use becomes important, as all models show a decrease in final energy use by 2050 compared to 2010. Despite the significantly increased GDP by 2050 (75-110\% increase from 2010), final energy use reduces by $15 \mathrm{EJ}$ in $80 \% \mathrm{DEF}$ (roughly $30 \%$ of today's final energy use), whereas it stays constant in $40 \%$ DEF. This implies that energy efficiency improvements must be initiated early in order to achieve final energy savings of sufficient scale to meet the $80 \%$ reduction target. Some policies related to energy efficiency have already been initiated, such as energy labeling, the Ecodesign Directive, and the implementation of smart metering. However, currently, no EU-wide policy instruments of substantial scale - compared, for example, to the EU emissions trading scheme for $\mathrm{CO}_{2}$ - have

${ }^{17}$ http://ec.europa.eu/energy/efficiency/eed/eed_en.htm. 
been implemented to trigger energy savings or energy efficiency. This is key for achieving the mitigation targets.

The models clearly reveal that in order to reach $80 \%$ emission reduction in the longterm, fundamental changes for decarbonizing the energy system are needed. Although the largest effort must occur after 2030, the foundations need to be laid out beforehand and considerable effort is required to facilitate such substantial changes. Sufficiently ambitious milestones for $\mathrm{CO}_{2}$ emissions, renewable deployment, and energy efficiency are needed in order to create a foundation for achieving the long-term target by 2050 . The discussion surrounding a potential 2030 framework (European Commission, 2013a) is in this respect only a first, but very timely and important step.

\section{Conclusion}

This paper describes the EMF28 multi-model assessment of the long- and mediumterm transformation of the European energy system. Thirteen models have been run using the same set of mitigation and reference scenarios under comparable technology assumptions. This model comparison is the first to relate its results to those of the Energy Roadmap presented by the European Commission in 2011. The EMF28 model comparison is used as a tool to determine what the EU energy system transition should look like in order to meet the EU's emission reduction goals and to be consistent with the international goal of staying below a $2^{\circ} \mathrm{C}$ rise in global average temperature. In this context, the analysis compares a reference scenario where the EU achieves $40 \%$ GHG reduction by 2050 with a mitigation scenario in which GHG emissions are reduced by $80 \%$. The scenarios build upon the cases that support the Energy Roadmap. In other words, the results of this exercise assess the robustness of the Energy Roadmap.

First, this study shows that, despite the models' differences, there are several pathways for achieving ambitious climate change mitigation in Europe. Nearly all the models can achieve the long-term target of reducing GHG emissions by $80 \%,{ }^{18}$ with only a moderate reduction in GDP (less than $0.7 \%$ by 2030 and below $2.3 \%$ by 2040). However, in some models, costs increase considerably after 2040, while others show costs increasing in a linear manner. This allows us to conclude that the $80 \%$ GHG reduction target is indeed challenging, especially after 2040 when a substantial amount of effort is required. It is important to mention that these results are derived from models that do not consider technical and political obstacles that could hinder the technological developments prescribed by our results.

This study also shows that it is critical to start a structural transformation of the fossil fuel-based energy system prior to 2030. It is necessary to set the right price signals in order to prevent the energy system from being locked into long-lasting

\footnotetext{
${ }^{18}$ The reported infeasibility in TIAM-UCL could be overcome if the restriction on the ability to import bioenergy into the EU was relaxed.
} 


\section{B. Knopf et al.}

investments in carbon technologies, such as coal-fired power plants. In general, policies should be designed to facilitate this transition through infrastructure development and behavioral and societal transformation.

Our findings show that the short-term target of a $20 \%$ GHG reduction by 2020 is not consistent with the cost-minimizing pathways for the long-term target of reducing GHG emissions by $80 \%$ in 2050 . Therefore, to facilitate the long-term transformation, a clear indication of binding targets for the period beyond 2020 would help investors to take the right strategic decisions. In addition, by setting targets for 2030, the EU would signal their willingness to contribute to the global climate mitigation effort. Concerning potential targets for 2030, a $40 \%$ reduction of GHG emissions - as indicated in the EU green paper (European Commission, 2013a) - could be in line with the long-term effort to reduce emissions by $80 \%$ in 2050 , but the model median would suggest setting an even more ambitious target.

The power sector is crucial for decarbonization, already shown by the reference scenario, as it has the ability to reduce emissions more than any other sector. However, as the mitigation target becomes more stringent, cutting emissions through the nonelectricity sectors becomes increasingly important. The transportation sector is the most costly sector to decarbonize, especially without significant biofuel imports to the EU. Allowing larger biofuel imports is likely to decrease the costs of mitigation. Energy efficiency is key for transformation across all the models, in all the scenarios, and for all levels of ambition. Achievement of energy efficiency, however, requires very strong policy instruments.

Despite the differences across the models, common features concerning the relevance of certain mitigation options leading to the achievement of the $80 \% \mathrm{GHG}$ reduction target exist:

- Reduction of energy intensity plays a key role in the mitigation strategies;

- Biomass use shows a greater than three-fold increase from 2010-2050; nonbiomassrenewables also increase considerably; all renewable energies together make up nearly $50 \%$ of electricity generation (model mean); among nonbiomass-renewables, wind is the most important with a seven-fold increase by 2050 , ultimately reaching a similar deployment level as nuclear, while solar PV represents a limited share;

- Nuclear is constant or moderately increases over time, but continues to make an important contribution in the electricity sector;

- While CCS plays also an important role in the default EMF28 scenarios, the alternative technology scenarios show that CCS is not necessarily required to meet the mitigation target;

- Intermittent renewables such as wind and solar PV contribute $27 \%$ of the future electricity mix by 2050 (model median). Therefore, new balancing power options are required, like the development of long-term and medium-term energy storage options and/or the expansion of the European electricity grid and the increase of interconnectors between Member States and demand-side measures. 
Table 3. Comparison of findings from the Energy Roadmap 2050 (European Commission, 2011e) with findings from this study.

Energy Roadmap 2050

EMF28

Decarbonization is possible and can be less costly than current policies in the long-term.

Higher capital expenditure and lower fuel costs.

Electricity plays an increasing role.

Electricity prices rise until 2030 and then decline.

Household expenditures will increase. Energy savings throughout the system are crucial.

Renewables rise substantially.

CCS has to play a pivotal role in system transformation.

Nuclear energy provides an important contribution.

Decentralization and centralized systems increasingly interact.
The models suggest that reaching the ambitious $80 \%$ GHG reduction target by 2050 is possible, as all the models except one found a solution. The abatement costs indicate that costs will increase with the level of ambition; however, the benefits of mitigation are not evaluated here. Some models suggest a strong increase in costs beyond 2040 (indicating the importance of technology development).

A transition towards capital-intensive low carbon technologies (nuclear, wind, solar) is observed in the models.

Electricity plays a greater role over time and becomes even more important for stringent policy scenarios; moreover, a nearly complete decarbonization of the electricity sector is mandatory for the achievement of the $80 \%$ reduction target.

This is not analyzed in detail. Electricity prices, as reported by the models, are mostly marginal prices (and not household prices). Marginal prices in the models stay stable or show a slight increase over time.

Not analyzed.

The conclusion from the model comparison is that: (i) absolute energy savings become more important as the stringency of the target rises, especially for sectors other than power generation, (ii) energy efficiency is crucial in all the models, especially in the short-term, and (iii) energy savings become even more important in the presence of technology constraints, for example, if CCS and/or nuclear power are not available.

Bioenergy and wind are of major importance in a low-carbon energy system. In the scenarios, solar PV plays only a minor role.

CCS is used when it is available in the models, but decarbonization is also possible without CCS. Nevertheless, CCS is an important option at the global level; therefore, the development of CCS technology is important for climate change mitigation.

The use of nuclear is more or less independent from the emissions reduction target because many models assume that the potential for nuclear expansion is limited. If CCS is not available, nuclear becomes more important.

This is not analyzed, but it is probably true as decentralized technologies such as solar PV and on-shore wind are entering the system while centralized technologies, such as nuclear, are still important for electricity generation. 


\section{B. Knopf et al.}

We have compared the EMF28 conclusions to those of the Energy Roadmap. The advantage of the EMF28 study compared to the Energy Roadmap is that it provides a comparative assessment based on a larger number and greater variety of models run by several organizations. We relate our findings to those provided in the communication document of the European Commission, which describes "ten structural changes for energy system transformation” (European Commission, 2011e), see Table 3.

This comparison shows that EMF28 results can support the general conclusions of the Energy Roadmap. One noticeable difference is the importance of CCS: While CCS plays an important role in the Energy Roadmap, especially as includes no scenario completely without CCS, in the EMF28, CCS only plays a role in scenarios where CCS is available, and the alternative technology scenarios show that CCS is not required to meet the mitigation target.

Future areas of research identified in this study include: (i) analysis of technology options in final consumption, including structural change; (ii) a more detailed analysis of all sectors, especially the transport sector; and (iii) an analysis of the implications and requirements of including a high share of intermittent renewables in the system in a technical and economic sense. These three streams of research could support the transformation that the European energy system must undergo in order to mitigate climate change.

\section{References}

Aalbers, R and J Bollen (2014). EU Energy Roadmap: Learning and intermittency. To appear in Climate Change Economics.

Anandarajah, G, S Pye, F Kesicki, W Usher and C McGlade (2011). TIAM-UCL Global Model Documentation. UK Energy Research Centre, London, UK. Available at http://www.ucl.ac. uk/energy-models/models/tiam-ucl/tiam-ucl-manual. Accessed on 15 October 2013.

Azar, C, K Lindgren, E Larson and K Möllersten (2006). Carbon capture and storage from fossil fuels and biomass - Costs and potential role in stabilizing the atmosphere. Climatic Change, 74(1-3), 47-79.

Blanford, GJ, RG Richels and TF Rutherford (2009). Feasible climate targets: The roles of economic growth, coalition development and expectations. Energy Economics, 31 (Supplement 2), S82-S93.

Blesl, M, T Kober, R Kuder and D Bruchof (2012). Implications of different climate policy protection regimes for the EU-27 and its member states through 2050. Climate Policy, 12(3), 301-319.

Böhringer, C and A Lange (2003). Efficiency, compensation, and discrimination: What is at stake when implementing the EU emissions trading scheme? ZEW Discussion Paper No. 03-73, Mannheim, Germany.

Böhringer, C and A Löschel (2006). Promoting renewable energy in Europe: A hybrid computable general equilibrium approach. The Energy Journal (Special Issue: Hybrid Modelling: New Answers to Old Challenges), 123-138.

Böhringer, C, A Löschel, U Moslener and TF Rutherford (2009). EU climate policy up to 2020: An economic impact assessment. Energy Economics, 31(2), 295-305. 
Bosetti, V, C Carraro, M Galeotti, E Massetti and M Tavoni (2006). WITCH: A world induced technical change hybrid model. Energy Journal, 27 (Special Issue 2), 13-38.

Calvin, K, L Clarke, V Krey, G Blanford, K Jiang, M Kainuma, E Kriegler, G Luderer and PR Shukla (2012). The role of Asia in mitigating climate change: Results from the Asia modeling exercise. Energy Economics, 34 (Supplement 3), S251-S260.

Capros, P, N Kouvaritakis, L Paroussos, P Karkatsoulis, K Fragkiadakis, D Van Regemorter, V Zaporozhets, Q Gharbi, P Le Mouel and K Delkis (2010). Description of GEM-E3 model improvements. Available at www.gem-e3.net. Accessed on 15 October 2013.

Capros, P, N Tasios, A De Vita, L Mantzos and L Paroussos (2012). Transformations of the energy system in the context of the decarbonisation of the EU economy in the time horizon to 2050. Energy Strategy Reviews, 1, 85-96.

Capros, P, D Van Regemorter, L Paroussos and P Karkatsoulis (forthcoming). The GEM-E3 model. To appear in IPTS' Scientific and Technical Report. Available at www.gem-e3.net. Accessed on 15 October 2013.

Clarke, L, C Böhringer and TF Rutherford, eds. (2009). International, U.S. and E.U. climate change control scenarios: Results from EMF 22 [Special Issue]. Enegy Economics, 31 (Supplement 2), S63-S306.

Criqui, P and S Mima (2012). European climate - energy security nexus: A model based scenario analysis. Energy Policy, 41, 827-842.

De Cian, E, V Bosetti and M Tavoni (2012). Technology innovation and diffusion in 'less than ideal' climate policies: An assessment with the WITCH model. Climatic Change, 114(1), 121-143.

De Cian, E, I Keppo, S Carrara, K Schumacher, H Förster, J Abrell, M Hübler, J Bollen and S Paltsev (2013). European-led climate policy versus global mitigation action: Implications on trade, technology, and energy. Climate Change Economics, 4(4), 1350015.

E3Mlab (2010). PRIMES Model version used for the 2010 scenarios for the European commission including new sub-models. Available at http://www.e3mlab.ntua.gr/e3mlab/PRIMESManual/The_PRIMES_MODEL_2010.pdf. Accessed on 15 October 2013.

Edenhofer, O, L Hirth, B Knopf, M Pahle, S Schloemer, E Schmid and F Ueckerdt (forthcoming). On the economics of renewable energy sources. Energy Economics, http://dx.doi. org/10.1016/j.eneco.2013.09.015.

Edenhofer, O, B Knopf, T Barker, L Baumstark, E Bellevrat, B Chateau, P Criqui, M Isaac, A Kitous, S Kypreos, M Leimbach, K Lessmann, B Magné, S Scrieciu, H Turton and DP van Vuuren (2010). The economics of low stabilization: Model comparison of mitigation strategies and costs. The Energy Journal, 31 (Special Issue 1), 223-241.

Edenhofer, O, K Lessmann, C Kemfert, M Grubb and J Kohler (2006). Induced technological change: Exploring its implications for the economics of atmospheric stabilization. The Energy Journal, Special Issue 1, 57-108.

EEA (2012). Annual European Union greenhouse gas inventory 1990-2010 and inventory report 2012. Available at http://www.eea.europa.eu/publications/european-union-greenhouse-gas-inventory-2012. Accessed on 15 October 2013.

Eurelectric (2009). Power choices — pathways to carbon-neutral electricity in Europe by 2050. Available at www.eurelectric.org/powerchoices2050.

European Climate Foundation (2011). Roadmap 2050. Available at http://www.roadmap2050. eu/downloads. Accessed on 15 October 2013.

European Commission (2011a). Commission staff working document: Impact assessment. Accompanying the communication: A Roadmap for moving to a competitive low carbon 


\section{B. Knopf et al.}

economy in 2050. Available at http://eur-lex.europa.eu/LexUriServ/LexUriServ.do?uri=SEC:2011:0288:FIN:EN:PDF. Accessed on 15 October 2013.

European Commission (2011b). Commission staff working paper: Final report of the Advisory Group on the Energy Roadmap 2050, Summary record of the PRIMES peer review meeting, results of the public consultation on the Energy Roadmap 2050. Available at http://ec. europa.eu/energy/energy2020/roadmap/doc/sec_2011_1569_1.pdf. Accessed on 15 October 2013.

European Commission (2011c). Commission staff working paper: Impact assessment. Accompanying the document Energy Roadmap 2050. Available at http://eur-lex.europa.eu/ LexUriServ/LexUriServ.do?uri=SEC:2011:0288:FIN:EN:PDF. Accessed on 15 October 2013.

European Commission (2011d). Communication: A Roadmap for moving towards a competitive low carbon economy in 2050. Available at http://eur-lex.europa.eu/LexUriServ/LexUriServ.do?uri=COM:2011:0112:FIN:EN:PDF. Accessed on 15 October 2013.

European Commission (2011e). Communication: Energy Roadmap 2050. Available at http:// eur-lex.europa.eu/LexUriServ/LexUriServ.do?uri=COM:2011:0885:FIN:EN:PDF. Accessed on 15 October 2013.

European Commission (2011f). White paper: Roadmap to a single European transport area towards a competitive and resource efficient transport system. Available at http://eur-lex. europa.eu/LexUriServ/LexUriServ.do?uri=COM:2011:0144:FIN:EN:PDF. Accessed on 15 October 2013.

European Commission (2012). Communication: Renewable energy: Progressing towards the 2020 target. Available at http://eur-lex.europa.eu/LexUriServ/LexUriServ.do?uri=COM:2011:0031: FIN:EN:PDF. Accessed on 15 October 2013.

European Commission (2013a). A 2030 framework for climate and energy policies. Available at http://eur-lex.europa.eu/LexUriServ/LexUriServ.do?uri=COM:2013:0169:FIN:EN:PDF. Accessed on 15 October 2013.

European Commission (2013b). Renewable energy progress report. Available at http://eur-lex. europa.eu/LexUriServ/LexUriServ.do?uri=COM:2013:0175:FIN:EN:PDF. Accessed on 15 October 2013.

European Council (2009). Presidency conclusions of the Brussels European Council. Available at http://register.consilium.europa.eu/pdf/en/09/st15/st15265.en09.pdf. Accessed on 15 October 2013.

European Council (2011). Conclusions of 4 February 2011. Available at http://www.consilium. europa.eu/uedocs/cms_data/docs/pressdata/en/ec/119175.pdf. Accessed on 15 October 2013.

European Parliament and the European Council (2009). Directive 2009/28/EC of the European parliament and of the council on the promotion of the use of energy from renewable sources and amending and subsequently repealing directives 2001/77/EC and 2003/30/EC. Official Journal of the European Union, L 140/16.

European Parliament and the European Council (2012). Directive 2012/27/EU. Official Journal of the European Union, L 315/1.

Eurostat (2012a). Electricity production and supply statistics. Available at http://epp.eurostat. ec.europa.eu/statistics_explained/index.php/Electricity_production_and_supply_statistics. Accessed on 31 January 2013.

Eurostat (2012b). Energy production and imports. Available at http://epp.eurostat.ec.europa.eu/ statistics_explained/index.php/Energy_production_and_imports. Accessed on 15 October 2013.

Eurostat (2012c). Gross inland energy consumption by fuel. Available at http://epp.eurostat.ec. europa.eu/tgm/table.do?tab=table \&init=1 \&language=en \& pcode $=$ tsdcc $320 \&$ plugin $=1$. Accessed on 15 October 2013. 
Förster, H, K Schumacher, E De Cian, M Hübler, I Keppo, S Mima and RD Sands (2013). European energy efficiency and decarbonization strategies beyond 2030 - A sectoral multimodel decomposition. Climate Change Economics, 4(Supplement 1), 1340004.

Holz, F and C von Hirschhausen (2013). The infrastructure implications of the energy transformation in Europe until 2050 - Lessons from the EMF28 modeling exercise. Climate Change Economics, 4(Supplement 1), 1340006.

Hübler, M and A Löschel (2013). The EU decarbonisation roadmap 2050 - What way to walk? Energy Policy, 55, 190-207.

Kanudia, A and M Gargiulo (2009). The Pan European TIMES Model.

Klein, D, G Luderer, E Kriegler, J Strefler, N Bauer, M Leimbach, A Popp, J-P Dietrich, F Humpenöder, H Lotze-Campen and O Edenhofer (forthcoming). The value of bioenergy in low stabilization scenarios: An assessment using ReMIND-MAgPIE. Climatic Change, http://dx.doi.org/10.1007/s10584-013-0940-z.

Knopf, B, B Bakken, S Carrara, A Kanudia, I Keppo, T Koljonen, S Mima, E Schmid and D van Vuuren (2013). Transforming the European energy system: Member states' prospects within the EU framework. Climate Change Economics, 4(Supplement 1), 1340005.

Knopf, B, O Edenhofer, C Flachsland, MTJ Kok, H Lotze-Campen, G Luderer, A Popp and DP van Vuuren (2010). Managing the low-carbon transition - from model results to policies. The Energy Journal, 31 (Special Issue 1 on The Economics of Low Stabilization), 223-245.

Koljonen, T and A Lehtilä (2012). The impact of residential, commercial, and transport energy demand uncertainties in Asia on climate change mitigation. Energy Economics, 34(Supplement 3), S410-S420.

Lempert, R (2002). Confronting surprise. Social Science Computer Review, 20(4), 420-440.

Luderer, G, C Bertram, K Calvin, E De Cian and E Kriegler (forthcoming). Implications of weak near-term climate policies on long-term climate mitigation pathways. To appear in Climatic Change, http://dx.doi.org/10.1007/s10584-013-0899-9. Accessed on 1 November 2013.

Luderer, G, V Bosetti, M Jakob, M Leimbach, JC Steckel, H Waisman and O Edenhofer (2012). The economics of decarbonizing the energy system - results and insights from the RECIPE model intercomparison. Climatic Change, 114(1), 9-37.

Paltsev, S and P Capros (2013). Cost concepts for climate change mitigation. Climate Change Economics, 4(Supplement 1), 1340003.

Paltsev, S, H Jacoby, J Reilly, Q Ejaz, F O'Sullivan, J Morris, S Rausch, N Winchester and O Kragha (2011). The future of U.S. natural gas production, use, and trade. Energy Policy, 39(9), 5309-5321.

Paltsev, S, J Reilly, H Jacoby, R Eckaus, J McFarland, M Sarofim, M Asadoorian and M Babiker (2005). The MIT emissions prediction and policy analysis (EPPA) model: Version 4. MIT Joint Program Report 125. Available at http://globalchange.mit.edu/files/document/ MITJPSPGC_Rpt125.pdf. Accessed on 15 October 2013.

Sands, RD, H Förster, K Schumacher and CA Jones (2013). Bio-electricity and land use in the future agricultural resources model (FARM). Climatic Change (EMF27 Special Issue), http://dx.doi.org/10.1007/s10584-013-0943-9.

Schroeder, A (2012). An electricity market model with generation capacity expansion under uncertainty, international workshop. Stochastic Programming for Implementation and Advanced Applications, July 3-6, 2012, Neringa, Lithuania.

Traber, T and C Kemfert (2012). German nuclear phase-out policy effects on European electricity wholesale prices, emission prices, conventional power plant investments and electricity trade., DIW Discussion Papers 1219. 


\section{B. Knopf et al.}

van Vuuren, DP, MGJ den Elzen, PL Lucas, B Eickhout, B Strengers, B van Ruijven, S Wonink and $R$ van Houdt (2007). Stabilizing greenhouse gas concentrations at low levels: An assessment of reduction strategies and costs. Climatic Change, 81(2), 119-159.

Weyant, J ed. (2004). EMF 19 alternative technology strategies for climate change policy [Special Issue]. Energy Economics, 26(6), 501-756. 